\section{Global-scale Assessment and Combination of SMAP with ASCAT (Active) and AMSR2} (Passive) Soil Moisture Products

Hyunglok Kim ${ }^{1}$, Robert Parinussa ${ }^{2}$, Alexandra G. Konings ${ }^{3}$, Wolfgang Wagner ${ }^{4}$, Michael H. Cosh $^{5}$, Venkat Lakshmi ${ }^{1}$, Muhammad Zohaib ${ }^{6}$, and, Minha Choi ${ }^{6}$ ${ }^{1}$ School of Earth Ocean and the Environment, University of South Carolina, Columbia, SC 29208 (hlkim@geol.sc.edu; vlakshmi@geol.sc.edu)

${ }^{2}$ VanderSat, Wilhelminastraat 43a, 2011 VK, Haarlem (rparinussa@vandersat.com)

${ }^{3}$ Department of Earth System Science, Stanford University, Stanford, CA, USA (konings@stanford.edu)

${ }^{4}$ Vienna University of Technology, Department of Geodesy and Geoinformation, Vienna, Austria

(wolfgang.wagner@geo.tuwien.ac.at)

${ }^{5}$ USDA-ARS-Hydrology and Remote Sensing Laboratory, Beltsville, MD, 21032 USA

(Michael.Cosh@ARS.USDA.GOV).

${ }^{6}$ Department of Water Resources, Graduate School of Water Resources, Sungkyunkwan University, Suwon, Republic of Korea (zohaib557@skku.edu; mhchoi@skku.edu)

This is the accepted manuscript version of this paper before copy-editing, formatting, technical enhancements and pagination. The finally published version (version of record) is available via https://doi.org/10.1016/j.rse.2017.10.026

(c) 2017. This manuscript version is made available under the CC-BY-NC-ND 4.0 license https://creativecommons.org/licenses/by-nc-nd/4.0/ 
Global-scale surface soil moisture (SSM) products retrieved from active and passive microwave remote sensing provide an effective method for monitoring near-real-time SSM content with nearly daily temporal resolution. In the present study, we first inter-compared global-scale error patterns and combined the Soil Moisture Active Passive (SMAP), Advanced Scatterometer (ASCAT), and Advanced Microwave Scanning Radiometer 2 (AMSR2) SSM products using a triple collocation (TC) analysis and the maximized Pearson correlation coefficient (R) method from April 2015 to December 2016. The Global Land Data Assimilation System (GLDAS) and global in situ observations were utilized to investigate and to compare the quality of satellite-based SSM products.

The average R-values of SMAP, ASCAT, and AMSR2 were 0.74, 0.64, and 0.65 when they compared with in situ networks, respectively. The ubRMSD values were $(0.0411,0.0625$, and $0.0708) \mathrm{m}^{3} \mathrm{~m}^{-3}$; and the bias values were $(-0.0460,0.0010$, and 0.0418$) \mathrm{m}^{3} \mathrm{~m}^{-3}$ for SMAP, ASCAT, and AMSR2, respectively. The highest average R-values from SMAP against the in situ results are very encouraging; only SMAP showed higher R-values than GLDAS in several in situ networks with low ubRMSD $\left(0.0438 \mathrm{~m}^{3} \mathrm{~m}^{-3}\right)$. Overall, SMAP showed a dry bias $\left(-0.0460 \mathrm{~m}^{3} \mathrm{~m}^{-3}\right)$ and AMSR2 had a wet bias $\left(0.0418 \mathrm{~m}^{3} \mathrm{~m}^{-3}\right)$; while ASCAT showed the least bias $\left(0.0010 \mathrm{~m}^{3} \mathrm{~m}^{-3}\right)$ among all the products.

Each product was evaluated using TC metrics with respect to the different ranges of vegetation optical depth (VOD). Under vegetation scarce conditions (VOD $<0.10)$, such as desert and semi-desert regions, all products have difficulty obtaining SSM information. In regions with moderately vegetated areas $(0.10<$ VOD $<0.40)$, SMAP showed the highest Signal-to-Noise Ratio. Over highly vegetated regions (VOD > 0.40) ASCAT showed comparatively better 
43 performance than did the other products.

44 Using the maximized R method, SMAP, ASCAT, and AMSR2 products were combined one by 45 one using the GLDAS dataset for reference SSM values. When the satellite products were 46 combined, R-values of the combined products were improved or degraded depending on the 47 VOD ranges produced, when compared with the results from the original products alone.

48 The results of this study provide an overview of SMAP, ASCAT, and AMSR2 reliability and 49 the performance of their combined products on a global scale. This study is the first to show 50 the advantages of the recently available SMAP dataset for effective merging of different 51 satellite products and of their application to various hydro-meteorological problems.

53 Keywords: Remotely sensed soil moisture retrievals, SMAP, ASCAT, AMSR2, Inter54 comparison, Triple collocation error estimator, Combining datasets 
Several methods for reproducing near-surface soil moisture (SSM) estimates from satellitebased microwave instruments have been proposed (Wagner et al., 1999; Njoku et al., 2003; Entekhabi et al., 2010; Jackson et al., 2010; Kerr et al., 2010). These investigations are crucial for understanding the hydrological cycle because SSM plays a key role in the partitioning of energy and water fluxes among the hydrosphere, biosphere, and atmosphere. In particular, SSM at global and regional scales is required in operational applications such as numerical weather prediction (NWP) at different time scale, climate and agricultural modeling, water resource and among the "Essential Climate Variables" (ECVs) in 2010 (GCOS, G., 2006).

Several satellite missions including the Soil Moisture and Ocean Salinity (SMOS) and Soil Moisture Active Passive (SMAP) have been dedicated to measuring global SSM through spaceborne remote sensing (Kerr et al., 2001; McColl et al., 2017). Specifically, SMAP was recently launched by the National Aeronautics and Space Administration (NASA) in January 2015 to monitor SSM and to detect the frozen or thawed state of soils (Entekhabi et al., 2010). Similarly, many other promising sensors (active and passive) capable of acquiring global SSM have been launched. These include the Advanced Scatterometer (ASCAT) onboard MetOp-A and B, the Advanced Microwave Scanning Radiometer 2 (AMSR2) onboard Global Change Observations Mission 1-Water (GCOM-W1), and the Microwave Radiation Imager onboard Feng Yun 
al., 2016). Although the SSM retrieved from these sensors has a coarse spatial resolution (20$50 \mathrm{~km}$ ), they have a short repeat time (1-3 days) that is suitable for many hydro-meteorological applications (Walker and Houser, 2004). In addition to improved retrieval of satellite-based SSM-data from space, new land surface models and ground measurements are providing useful SSM information about near-surface to deeper layers. Ground-based SSM measurements reflect the true value of SSM at point scale (Brocca et al., 2007; Famiglietti et al., 1999; Nguyen et al., 2017). Moreover, many previous studies have shown that point-based ground measurements can reflect temporal SSM dynamics of the field mean SSM value (Vachaud et al., 1985; Wagner et al., 2008; Brocca et al., 2009); therefore, such ground measurements are essential for validation and evaluation of both satellite-based and land surface model SSM products. In situ datasets have limitations in terms of vertical and spatial representation and spatial extent, especially for global-scale data analysis. For this reason, modeled SSM products such as those from the Modern-Era Retrospective Analysis for Research and Applications-Land (MERRA-Land) and Global Land Data Assimilation System (GLDAS), which are based on merged satellite and gauge-based datasets, are sometimes used for validation and calibration studies (Brocca et al., 2011; Chen et al., 2013; Al-Yaari et al., 2014a and 2014b). Not only satellite-based SSM data but also land surface models are tools that provide sufficiently reasonable guidance of SSM and profile SM information worldwide over regions where in situ observations are sparse (Lakshmi et al., 2004; Albergel et al., 2012).

Understanding the spatio-temporal error characteristics of different satellite SSM products is of great importance for operational applications. In many previous studies, the consistency of satellite-based SSM products have been investigated using reference SSM values, including data from the Advanced Microwave Scanning Radiometer for EOS (AMSR-E), SMOS, 
ASCAT, and AMSR2. Such studies have shown that each product has different error characteristics under different surface and environmental conditions (Dorigo et al., 2010; Gruhier et al., 2010; Kim et al., 2015a; Konings et al., 2011; Leroux et al., 2014; Wagner et al., 2014; Griesfeller et al., 2016; Burgin et al., 2017; Cho et al., 2017). Because each satellitebased SSM product has shown different performance depending upon land cover conditions, sensor specifications, and SSM retrieval algorithms, the merging of these different datasets is regarded as a promising approach by which to establish a level of meta-performance superior to what is possible using the individual products (Liu et al., 2011; Liu et al., 2012; Kim et al., 2015b).

Combining different satellite-based SSM products provides a mechanism for overcoming the drawbacks of an individual product (Houser et al., 1998; Liu et al., 2012; Wagner et al., 2012; Dorigo et al., 2015). To generate a combined SSM product, both passive and active microwave SSM datasets have been used. Liu et al. (2012) combined four passive and two active microwave products as part of the European Space Agency (ESA) Program on Global Monitoring of ECV, which was initiated in 2010 and is known as the Climate Change Initiative (CCI; http://www.esa-soilmoisture-cci.org). Starting from 1 November 1978, the ECV CCI products have provided combined SSM products for long observation periods and preserved the relative dynamics of the original satellite-derived products (Dorigo et al., 2017). Furthermore, Kim et al. (2015b) introduced a method of combining two different parent datasets by maximizing the temporal correlation with a reference dataset. If the reference value (e.g., a modeled SSM dataset) is assumed to be the highest-quality SSM dataset, the maximized $\mathrm{R}$ method is capable of improving the temporal correlation coefficient values between the combined and reference datasets when two parent products are combined. Because each 
product performs differently under different environmental conditions, complementary aspects can be distinctly observed. However, the reference values do not always represent the highestquality dataset, which can lead to deterioration of the parent products. Nonetheless, in many cases, the combined dataset shows generally superior results compared with individual datasets by showing higher values of temporal correlation with ground-based measurements.

In the present study, we first inter-compared and combined a recently available SMAP dataset with specific versions of ASCAT and AMSR2 SSM products using statistical metrics including triple collocation analysis and presented the results through the Taylor diagram. As previously mentioned, SSM is retrieved using many different algorithms that can show better or worse performance over some areas even though the observational system is identical. Wagner et al. (2014) clearly showed that different performance rankings of SSM datasets (and subsequent conclusions) could be obtained by specific selection of processing and interpretation of the datasets. Considering this point, the present study compares algorithms and metrics to determine whether a particular satellite-based SSM product enables improved quality and performance when combined with other datasets.

The three main objectives of this study were as follows. First, we aimed to assess the global performance of individual SSM products (from SMAP, ASCAT, and ASMR2) by comparison with ground-based and model SM datasets produced from April 2015 to December 2016.

Second, we aimed to investigate global-scale error patterns of SMAP, ASCAT, and AMSR2 using triple collocation analysis; with performance assessments to consider different land cover classifications and vegetation fractions. 
Third, we aimed to combine SMAP with other satellite-based SSM products and evaluate the results to investigate practical applications of the newly available SMAP dataset. Regarding the combined SSM product, the SMAP SSM was considered a candidate product for combination with others.

This research provides novel insight into the use of the recently available SMAP SSM dataset in various practical applications including satellite-based SSM data merging, assimilation in NWP, and hydrological modeling.

\section{Materials and Methods}

\subsection{Remotely sensed surface soil moisture}

SMAP, ASCAT, and AMSR2 were evaluated against GLDAS and in situ SSM datasets, which were assumed to be reference SSM values. Because the SMAP dataset was made available in April 2015, the period of analysis was April 2015 to December 2016. All three satellite-based SSM datasets were projected to the WGS84 geographic grid and resampled using the nearest neighbor distance algorithm to establish a uniform georeferenced $0.25^{\circ}$ grid, which is the same as that used in the GLDAS datasets (Rüdiger et al., 2009; Al-Yaari et al., 2014b). In addition, the GLDAS datasets were reconstructed from UTC time-based to local time-based in order to match the SMAP, ASCAT, and AMSR2 local overpass times. This reconstruction was achieved by considering the navigational time zone based on longitude and by neglecting local statutory deviations (Fig. S1). Similarly, data from the in situ datasets were extracted at a time closest to the local overpass time of each satellite product. Because the ISMN provides hourly data, we set a one-hour threshold for the maximum time difference between the in situ and satellite overpass time (local time). For instance, we used the in situ datasets of 06:00 - 07:00 A.M. for 
the half orbit SMAP, 9:00 - 10:00 P.M. for the descending path of ASCAT, and 01:00 - 02:00 A.M. for the ascending path of AMSR2. In order to calculate sound results, the in situ stations for which the corresponding pixels had more than 100 data points in time were selected for all satellites and GLDAS products.

\subsubsection{SMAP soil moisture retrievals}

Successfully launched in January 2015, the SMAP mission is the first Earth observation satellite developed by NASA in response to the National Research Council's Earth Science Decadal Survey (Entekhabi et al., 2010; Colliander et al., 2017). This mission was designed to enhance scientific understanding of the interaction between the Earth's surface and atmosphere to predict natural disasters and improve climate forecasting. The main goal of the SMAP mission is to obtain high-accuracy SSM information. The accuracy requirements of SMAP mission specify that SSM should be retrieved with ubRMSE of $0.04 \mathrm{~m}^{3} \mathrm{~m}^{-3}$ accuracy in low or moderately vegetated areas in order to use this data for effective monitoring and prediction of natural hazards such as droughts, floods, and dust outbreaks. SMAP carries an L-band radiometer $(1.41 \mathrm{GHz})$ and rotating reflector radar (1.26 GHz non-imaging SAR), which was designed to provide a conical scanning-antenna beam. SMAP has a near-polar sun synchronous orbit and overpasses the Equator at approximately 06:00 and 18:00 local time (LT) in descending and ascending orbits, respectively. In addition, SMAP was expected to provide different SSM resolutions, at 3, 9, and $36 \mathrm{~km}$. However, only the $36 \mathrm{~km}$ and enhanced L3 radiometer $9 \mathrm{~km}$ resolution datasets are currently available because the radar unit failed to transmit after 7 July 2015. For this reason, only a few months of the active/passive combined SSM datasets are available. The data from the descending half-orbit has been used as input for 
SSM retrievals because of the equilibrium assumption of early morning thermal conditions for hydro-meteorological variables (e.g., air, vegetation, and near-surface soil). In this study, we used the $36 \mathrm{~km}$ half-orbit descending SMAP Level-3 radiometer-based SSM product because it is expected that the descending overpass time of SMAP (06:00 LT) is closest to thermal equilibrium and uniformity among the SSM conditions available at this time (Hornbuckle et al., 2005; Entekhabi et al., 2010; Entekhabi et al., 2014; Das and Dunbar, 2015). It is this product (SMAP Level-3) that is hereafter referred to as SMAP. All radiometer data products from SMAP were obtained from the National Snow and Ice Data Center (NSIDC DAAC, http://nsidc.org/data/smap/).

The SMAP dataset was masked where soil temperature was below $273.15 \mathrm{~K}$ from the GLDAS 0-10 cm layer, for SSM lower than $0.02 \mathrm{~m}^{3} \mathrm{~m}^{-3}$ and higher than $0.50 \mathrm{~m}^{3} \mathrm{~m}^{-3}$, and when the flag for the freeze/thaw fraction indicated an unfrozen soil and when the retrieval quality flag was set as 'recommended'. The validation grid processing corresponds to the SMAP data version R14010. Please refer to O'Neill, et al. (2015) for detailed description of the algorithm theoretical basis document for the SMAP.

\subsubsection{ASCAT soil moisture retrievals}

The ASCAT sensors onboard the Meteorological Operational A and B (MetOp-A and MetOpB) satellites are active microwave remote-sensing instruments operated by the European organization for the exploitation of METeorological SATellites (EUMETSAT). METOP-A was launched in October 2006. ASCAT acquires radar backscatter measurements at a frequency of 5.3 GHz (C-band), has a spatial resolution of $25 \mathrm{~km}$ with a 1-3 day revisit time (Scipal et al., 2008a; Naeimi, 2012; Wagner et al., 2013). The ASCAT overpasses at 09:30 LT in descending 
219 orbit, and at 21:30 LT in ascending orbit. ASCAT SSM retrievals are distributed by the EUMETSAT'S Satellite Application Facility as Support to Operational Hydrology and Water Management (H-SAF). The change-detection method was introduced by Wagner et al. (1999) and improved by Naeimi et al. (2009). Specifically, the SSM content $\left(\mathrm{m}_{\mathrm{s}}\right)$, or the so-called degree of saturation, can be calculated from the basic ASCAT measurement, which is the backscattering coefficient $\left(\sigma^{\circ}\right)$ measured at a reference angle of $40^{\circ}$ and based on the method of Wagner et al. (1999). For details about the change detection algorithm, please refer to Wagner et al. (2013).

The porosity values were estimated by applying the equations of Saxton and Rawls (2006). The texture characteristics were obtained from the Harmonized World Soil Database (FAO/IIASA/ISRIC/ISS-CAS/JRC, 2009). In this study, we focused on ASCAT SSM products for a $25 \mathrm{~km}$-swath grid generated from the EUMETSAT Data Service Centre, which are available for download through the EUMETSAT website (https://rs.geo.tuwien.ac.at/products/). The ASCAT dataset was masked out to remove grid cells for wetland fractions above $15 \%$, topographic complexity above $20 \%$, SSM error above $10 \%$, and soil temperature below the freezing point (Draper et al., 2012; Parrens et al., 2012; Paulik et al., 2014). It is worth noting that all three products have different flag information for masking abnormal SSM datasets; thus, if new flag information is developed in future datasets, it would help provide masks for retrieval of higher quality SSM datasets.

In addition, different ASCAT SSM products, such as the time series products distributed by HSAF (http://www.geo.tuwien.ac.at), may show better quality than the NRT data found in the EUMETSAT archive. However, owing to the availability of the dataset, we used EUMETSAT NRT products in this study. We considered only the descending path of the ASCAT SSM product, hereafter referred to as ASCAT, because it showed slightly better statistical metrics 
when compared with in situ observations (Table S1).

\subsubsection{AMSR2 soil moisture retrievals}

The AMSR2 sensor onboard the GCOM-W1 platform was launched in May 2012 (Kachi et al., 2013). This satellite mission is the successor of Aqua AMSR-E, which ceased operation in October 2011. AMSR2 is a passive microwave remote sensing instrument developed by the Japan Aerospace Exploration Agency (JAXA) with the cooperation of NASA. It utilizes microwave frequency bands: $\mathrm{C} 1(6.9 \mathrm{GHz}), \mathrm{C} 2(7.3 \mathrm{GHz})$, and $\mathrm{X}(10.6 \mathrm{GHz})$, for SSM measurements and provides a 1,450 km swath-width. It has three different ground resolutions that depend on frequency channels (C1-band: $24 \times 42 \mathrm{~km}, \mathrm{C} 2-$ band: $34 \times 58 \mathrm{~km}$; X-band: 35 x $62 \mathrm{~km}$ ) with a revisit time of one to two days (Maeda and Taniguchi, 2013). The AMSR2 crosses the equator at 01:30 LT and 13:30 LT in descending and ascending orbits, respectively. AMSR2-based SSM products can be derived from two widely used algorithms: the JAXA and Land Parameter Retrieval Model (LPRM) (Maeda \& Taniguchi, 2013; Kim et al., 2015a; Parinussa et al., 2016; van der Schalie et al., 2017). Both algorithms utilize a simple radiative transfer model (Mo et al., 1982) based on microwave emissions from the land surface, which were measured in terms of satellite brightness temperature $\left(T_{b}\right)$. The JAXA algorithm produces SSM products in the X-band only, whereas the LPRM products are available in both C- and Xband microwave frequencies. Moreover, the LPRM algorithm retrieves the vegetation optical depth (VOD) product along with the SSM product from AMSR2 $\mathrm{T}_{\mathrm{b}}$ measurements using the Microwave Polarization Difference Index (Owe et al., 2001; Meesters et al., 2005). VOD is a measure of vegetation water content and aboveground vegetation structure, and has been used 
for estimates of aboveground vegetation (Konings and Gentine, 2017). In this study, we used the AMSR2 descending overpass VOD to evaluate the different satellite SSM products in terms of vegetation fraction.

Furthermore, for this study we used the most recently improved LPRM AMSR2 dataset (descending path), hereafter referred to as AMSR2. This dataset has shown significantly improved ability, relative to existing LPRM algorithms, for capturing the temporal variability of SSM when compared with in situ observations (Parinussa et al., 2016; van der Schalie et al., 2017). Moreover, in comparison with other satellite-based SSM datasets, AMSR2 can provide SSM and VOD retrieval at three different frequencies. Therefore, it can minimize the effects of contamination from radio frequency interference (RFI), which means that the C1-, C2-, and X-bands can be used for selective SSM and VOD retrieval (de Nijs et al., 2015). The C-band frequency is usually expected to have higher-quality SSM information than with the X-band because of the deeper penetration provided by lower frequencies. Therefore, we used the newly developed RFI detection method, the standard error of estimate (SE) proposed by de Nijs et al. (2015), to set the lower frequency-based SSM product as a priority product for AMSR2 (Fig. S2). We note that care in the use of LPRM AMSR2 products distributed by JAXA is encouraged because Cho et al. (2016) found that Version 1 LPRM AMSR2 C1- and C2-band retrieved SSM showed unusual temporal patterns when compared with the modeled and X-band SSM products. The AMSR2 dataset over densely vegetated regions was screened using the VOD value and setting an upper threshold of 0.6, which was retrieved along with the SSM values (Meesters et al., 2005; Owe et al., 2008) (Fig. 1a). Similar to the SMAP and ASCAT dataset preprocessing, when the soil temperature was below $273.15 \mathrm{~K}$ (freezing point of water), the AMSR2 dataset was masked out. 


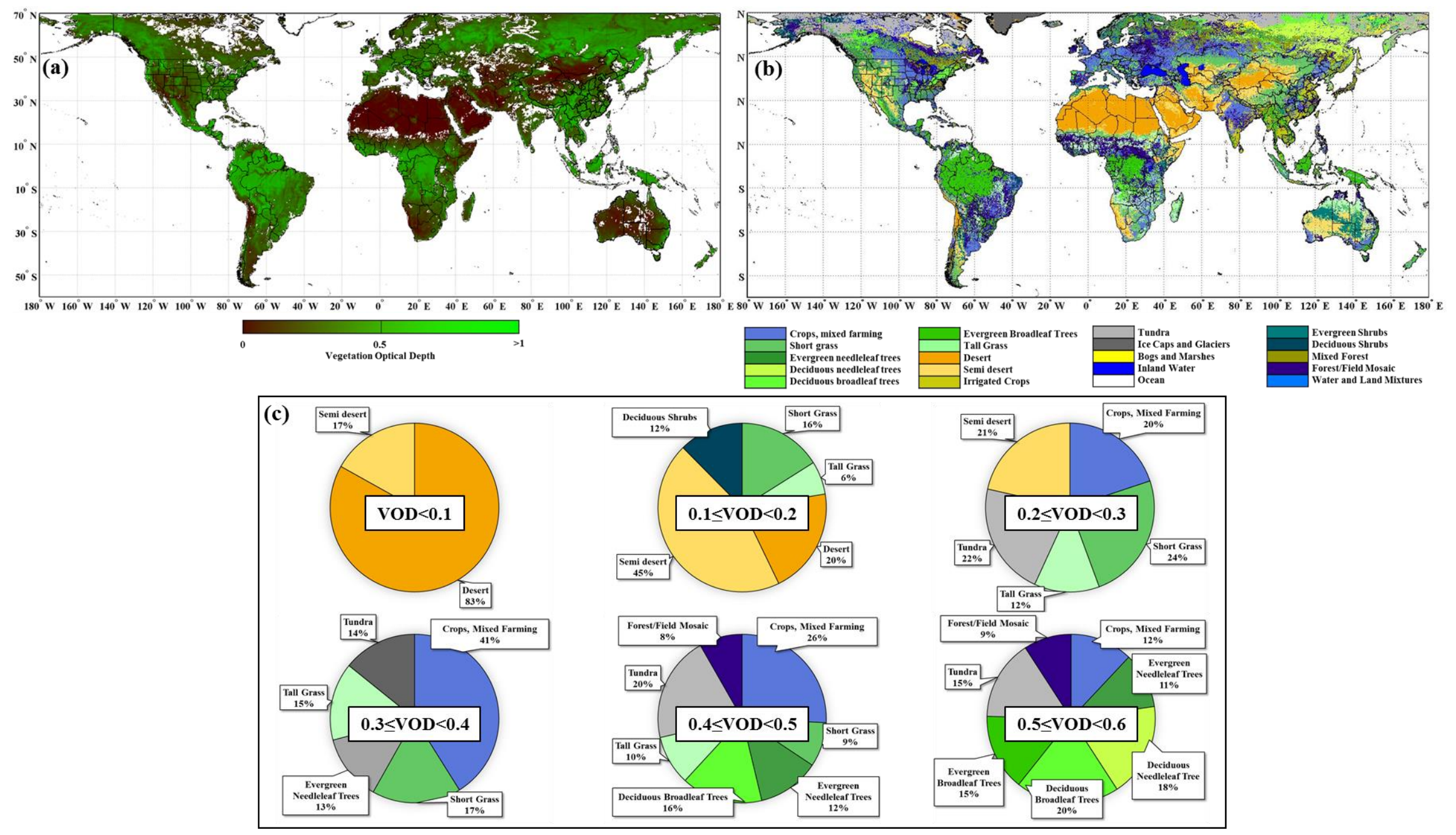

Figure 1. (a) Global map of average vegetation optical depth from the AMSR2 descending path for January 2015 to December 2016. (b) Global land cover classification from the BATS model. (c) Pie charts indicating land cover classification from the BATS model based on six VOD ranges. 


\subsection{GLDAS soil moisture product}

293 Along with the satellite-based SSM datasets, Global Land Data Assimilation System-1 294 (GLDAS-1) Noah, which became available in 2000, also provides numerous atmospheric and

295 land surface variables with a temporal resolution of $3 \mathrm{~h}$ and a spatial resolution of $0.25^{\circ}$. The model is constrained to using heterogeneous forcing datasets including National Oceanic and Atmospheric Administration (NOAA)/GDAS atmospheric analysis, the spatially and temporally disaggregated NOAA Climate Prediction Center Merged Analysis of Precipitation field, and observation-based radiation fields derived from the Air Force Weather Agency's Agricultural Meteorological modeling system (Rodell et al., 2004). GLDAS has been widely used as a reference dataset for merging active and passive products (Liu et al., 2011a; Kim et al., 2015b). In this study, the SSM of the top $10 \mathrm{~cm}$ layer from GLDAS-1-Noah, hereafter referred to as GLDAS, was utilized as the reference value of SSM when combining satellitebased SSM products based on the maximized R method. In addition, it is worth noting that some depth mismatch between the satellite-based SSM (top few $\mathrm{cm}$ ) and the GLDAS SSM (10 $\mathrm{cm}$ ) is certainly expected; however, GLDAS-1 Noah SSM represents 0-10 cm depth, which implies that the GLDAS SM contains information about depths shallower than $10 \mathrm{~cm}$ as well. Moreover, in many previous studies, the top $10 \mathrm{~cm}$ SM-dataset from land surface models was utilized to validate and improve various satellite-based SSM retrievals (Dorigo et al., 2010; Liu et al., 2012; Wagner et al., 2012).

GLDAS SSM was validated with in situ SSM datasets from the International Soil Moisture Network (ISMN) to verify its reliability, as discussed in Section 3.1. 


\subsection{International Soil Moisture Network (ISMN)}

316 To evaluate the individual remotely sensed SSM products, we used in situ observations from

317 the ISMN. ISMN is a web-based data center that collects and organizes in situ soil moisture measurements from different operational networks and validation campaigns, and freely shares the data with users through a web interface (https://ismn.geo.tuwien.ac.at/; accessed on 4. Oct. 2017). The soil moisture data provided by ISMN are crucial for validating different satellitebased SSM retrievals and land surface models and for studying the climate system (Dorigo et al., 2011; Dorigo et al., 2013; Oshner et al., 2013). The ISMN soil moisture has been widely used in many validation studies. Currently, the ISMN holds numerous soil moisture datasets provided by more than 2000 measurement stations and operated by more than 55 different networks (Dorigo et al., 2015). In this study, however, we chose only stations measuring SM at a depth of $10 \mathrm{~cm}$ or less with data covering the study period (April 2015 to December 2016). Moreover, to obtain robust statistical results, we masked the stations for which the corresponding pixel had less than 100 data points in time (for GLDAS and the three satellite products). Furthermore, if more than one station was situated in a grid pixel, we took an average of all station values. After this preprocessing step, the data at 213 sites in eight different monitoring networks remained, most of which are located in the United States and Europe (Fig. 2). All datasets were quality controlled, and were cross-screened in order to retain only overpass times and pixels for which all satellite-based datasets were attainable. A brief description of the ISMN used is summarized in Table 1. A detailed description of the ISMN used is provided in the Supplementary Data file. 


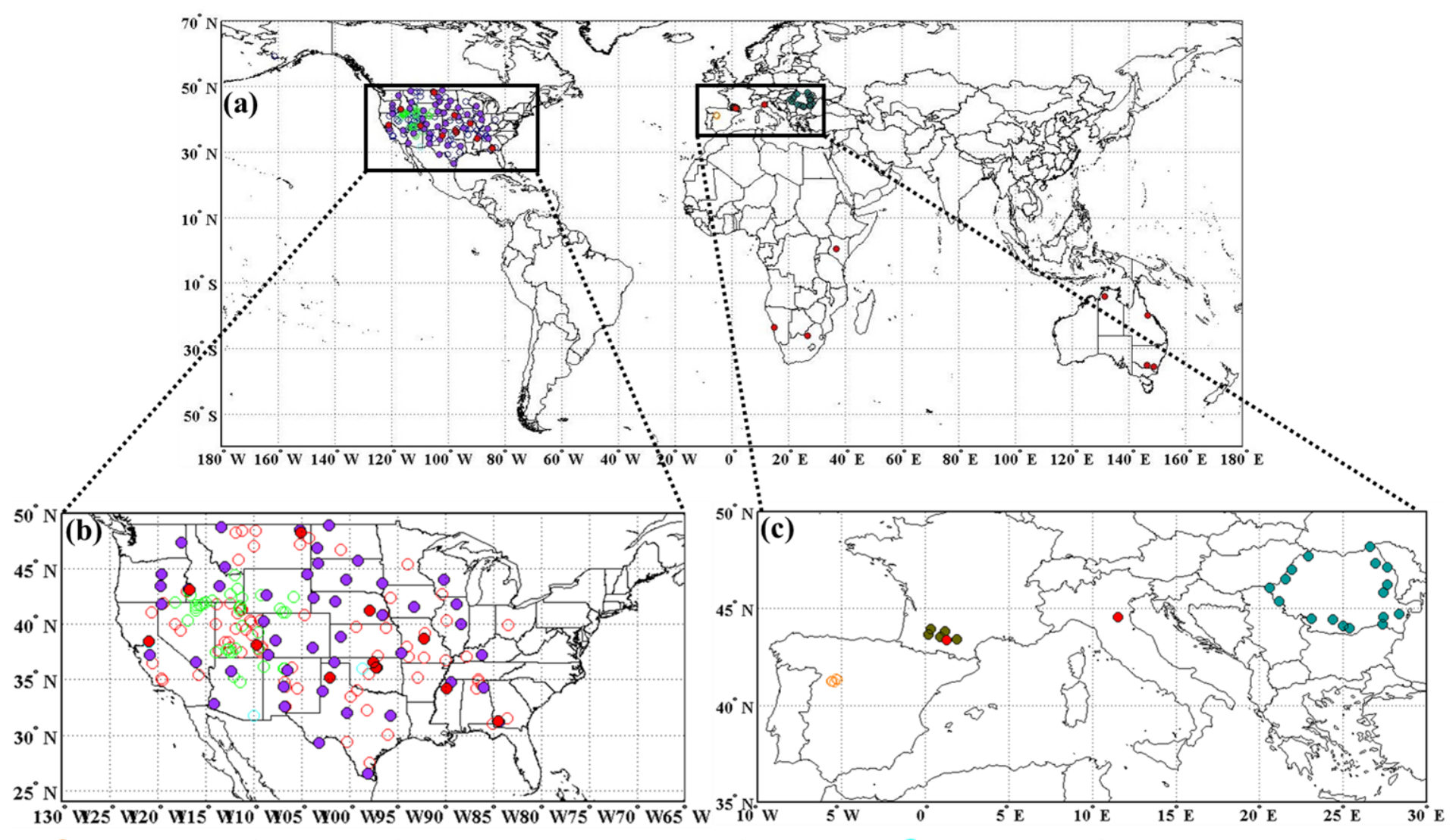

Figure 2. a) Locations of the ISMN in-situ SM stations used for validation in this study. There are 5 out of 20 for REMEDHUS, 17 out of 19 for RSMN, 76 out of 1,018 for SCAN, 5 out of 68 for SMOSMANIA, 38 out of 1,393 for SNOTEL, 3 out of 291 for SOILSCAPE, 49 out of 486 for USCRN, and 20 out of 73 for COSMOS stations. The majority of stations are concentrated in (b) the USA and (c) Europe. The number of stations in the maps represents the stations that passed the quality control and cross-screening processes. 
343 Table 1. ISMN summary

\begin{tabular}{|c|c|c|c|c|c|}
\hline $\begin{array}{l}\text { Network } \\
\text { Name }\end{array}$ & Country & No. of station used & Depth used (cm) & Type of sensor & References \\
\hline REMEDHUS & Spain & 5 & $0-5$ & Stevens HydraProbe & Sancheze et al., (2012) \\
\hline RSMN & Romania & 17 & $0-5$ & $5 \mathrm{TM}$ & http://assimo.meteoromania.ro/ \\
\hline SCAN & $\begin{array}{l}\text { United } \\
\text { States }\end{array}$ & 76 & $0-10$ & $\begin{array}{c}\text { Hydraprobe analog (5.0 volt) } \\
\text { Hydraporbe Digital Sdi-12 (2.5 Volt) } \\
\text { Hydraprobe Analog (2.5 Volt) n.s. } \\
\text { Hydraprobe Digital Sdi-12 Thermistor (linear) }\end{array}$ & http://www.wcc.nrcs.usda.gov/scan \\
\hline SMOSMANIA & France & 5 & $0-10$ & $\begin{array}{c}\text { ThetaProbe ML2X } \\
\text { ThetaProbe ML3 }\end{array}$ & Albergel et al., (2008) \\
\hline SNOTEL & US & 38 & $0-10$ & $\begin{array}{c}\text { Hydraprobe analog (5.0 volt) } \\
\text { Hydraprobe Analog (2.5 Volt) } \\
\text { Hydraprobe Digital Sdi-12 (2.5 Volt) }\end{array}$ & http://www.wcc.nrcs.usda.gov/snow \\
\hline SOILSCAPE & US & 3 & 5 & EC5 & Moghaddam et al., (2016) \\
\hline USCRN & US & 49 & $0-10$ & Stevens Hydraprobe II Sdi-12 & Bell et al., (2013) \\
\hline COSMOS & US & 20 & Variable over time and space & Cosmic-ray Probe & Zreda et al., (2012) \\
\hline
\end{tabular}

344 


\subsection{The Biosphere-Atmosphere Transfer Model}

346

347

348

349

350

351

352

353

354

355

356

357

358

359

360

361

362

363

364

365

366

367

The Biosphere-Atmosphere Transfer Model (BATS) is a simple boundary layer scheme first introduced by Dickinson et al. (1981). Subsequent improvements in the model have been well documented by Dickinson (1984), Dickinson et al. (1986), and Dickinson et al. (1993). The BATS scheme considers three soil layers and one vegetation layer for predicting seven variables: canopy temperature, surface soil temperature, subsurface soil temperature, surface soil water, root zone soil water, total soil water, and canopy water content. The surface cover and soil types are based on Wilson and Henderson-Sellers (1985). This scheme was designed for incorporation into the National Center for Atmospheric Research Community Climate Model; however, its many features have also been used in other land surface models (Liang et al., 1994). In this study, land cover classifications from the BATS model were used to evaluate the performance of the individual and combined SSM products for different land cover types.

\subsection{Data preparation}

Satellite-based SSM retrieval from space provides observations of the thin top-layer SSM; however, in situ soil moisture sensors are installed at a certain depth below the surface and can sense the soil moisture profile. Therefore, a depth discrepancy occurs between satellite and in situ sensors that has been noted and widely discussed in previous studies (Al-Yaari et al., 2014a; Dorigo et al., 2015; Shellito et al., 2016; Zohaib et al., 2017). Simple techniques like the exponential filter make it possible to overcome the depth discrepancy between ground measurements and satellite SSM products by estimating root-zone soil moisture, as proposed by Wagner et al. (1999). In their study, this semi-empirical approach generally improved the R-values with respect to in situ measurements. We calculated the satellite profile layer soil 


$$
K_{n}=\frac{K_{n-1}}{K_{n-1}+e^{-\left(\frac{t_{n}-t_{n-1}}{T}\right)}},
$$
5

moisture using an exponential filter developed by Wagner et al. (1999) and given by Albergel et al. (2008) in its recursive form as follows:

$$
S W I_{m n}=S W I_{m(n-1)}+K_{n}\left(\mathrm{~ms}\left(\mathrm{t}_{n}\right)-\mathrm{SWI}_{m(n-1)}\right),
$$

where $S W I_{m(n-1)}$ is the profile soil moisture estimate at $\mathrm{t}_{\mathrm{n}-1}$, and $\mathrm{ms}\left(\mathrm{t}_{\mathrm{n}}\right)$ is the SSM estimate at $\mathrm{t}_{\mathrm{n}}$. The gain $K$ at a time $\mathrm{t}_{\mathrm{n}}$ is given by

where $T$ represents the characteristic time length in days, which is considered a proxy for all processes that affect the temporal dynamics of subsurface soil moisture such as layer depth, soil hydraulic properties, evapotranspiration, runoff, and vertical heterogeneity of the soil properties (Albergel et al., 2008). In previous studies, an optimum $T\left(T_{\text {opt }}\right)$ value approach was proposed based on the Nash-Sutcliffe score, to match the profile soil moisture at each in situ station. The exponential filter has been detailed in various studies (Wagner et al., 1999; Albergel et al., 2008; Ford et al., 2014). In the present study, we also used $T_{\text {opt }}$ to match the depth of satellite and in situ soil moisture at each station. SWI was only considered when satellite-based SSM datasets were compared with in situ observations. 


\subsection{Statistic metrics used for the comparison and combination methodology}

389

390

391

392

393

394

395

396

397

398

399

400

401

402

403

404

405

406

407

408

409

410

\subsubsection{Comparison metrics and triple collocation error estimator}

We considered three conventional statistical indicators to evaluate each remotely sensed SSM $\left(\mathrm{SSM}_{S A T}\right)$ : the Pearson correlation coefficient $(\mathrm{R})$, bias, and unbiased root-mean-square deviation (ubRMSD). These metrics were considered for validation of three satellite and model datasets against in situ observations, and for validating the combination of three satellite products. We assumed that in situ datasets have the highest quality SSM values in order to calculate the unbiased RMSD and bias values. In addition, we set the GLDAS datasets as the highest-quality reference SSM values for combining two parent products, which is an inevitable assumption for combining processes via the maximized $\mathrm{R}$ method. All conventional statistical metrics were applied only when the number of data points used for calculation was larger than 100. The ubRMSD metric was considered to investigate each product's RMSD value after removing a possible bias from ancillary information (e.g., porosity) (Albergel et al., 2012; AL-Yarri et al., 2014). Only the R-values at $\mathrm{p}<0.05$ were considered in the comparison analysis.

In order to provide global-scale analysis of the satellite-based SSM products, we considered triple collocation (TC) statistics. TC analysis enables evaluation of global-scale satellite-based SSM products without having additional reference datasets as conventional metrics. Through TC analysis, we could calculate the random error variances of three collocated datasets. Most recently, Gruber et al. (2016) suggested the use of decibel units of signal-to-noise ratio (SNR[dB], Equations 3-4), which is physically intuitive and has low sensitivity to estimation uncertainties. In addition, on the basis of the SNR value, the fractional mean squared error (fMSE, Equation 5) and linear correlation coefficient $\left(\mathrm{R}_{\mathrm{i}}^{2}\right.$, Equation 6) of the individual 
411 datasets could be calculated. Details of the TC analysis have been presented in previous 412 research (Scipal et al., 2008b; Draper et al., 2013; Su et al., 2014a and 2014b; Gruber et al., 413 2016).

414 TC assumes independent errors; therefore, we selected SSM products with derivations as 415 different as possible because similarly derived datasets might have partially correlated errors. 416 This might happen for AMSR2 and SMAP, for example, because they are both radiometers. 417 For these reasons, we repeated the TC calculations twice: once with a triplet including SMAP, 418 ASCAT, and GLDAS and once with a triplet including AMSR2, ASCAT, and GLDAS. Then 419 we used the ASCAT TC statistics from the SMAP triplet because ASCAT is more dissimilar in 420 frequency to SMAP than AMSR2. However, the error estimates for each product were 421 consistent when using the two different triplets, we expect that this process did not impact the 422 final results discussed later.

423 Aside from the value of error variance, the SNR metric enables objective comparison of the 424 error metric among various satellite SSM products (Gruber et al., 2016) because the individual 425 SSM $_{\text {SAT }}$ has a subjective scaling of the range of SSM variation.

426

$$
S N R_{S A T_{1}}=\frac{\operatorname{cov}\left(\mathrm{SSM}_{\mathrm{SAT}_{1}}, \mathrm{SSM}_{\mathrm{SAT}_{2}}\right) \cdot \operatorname{cov}\left(\mathrm{SSM}_{\mathrm{SAT}_{1}}, \mathrm{SSM}_{\mathrm{GLDAS}_{\mathrm{S}}}\right)}{\operatorname{cov}\left(\mathrm{SSM}_{\mathrm{SAT}_{2}}, \mathrm{SSM}_{\mathrm{GLDAS}}\right) \cdot \operatorname{var}\left(\varepsilon_{\mathrm{SAT}_{1}}\right)}
$$

427 where the subscript 1 and 2 denotes two independent satellite dataset, cov is the covariance of 428 the two independent satellites dataset or a satellite and GLDAS dataset, and var is variance of 429 the $\mathrm{SAT}_{1}$ error.

430 By taking SNR with the decadic logarithm, the SNR was distributed symmetrically around zero, 431 which gave easier and clearer insight into the value of SNR interpretation. 
433 Every positive or negative $3 \mathrm{~dB}$ interval of SNR[dB] indicates an additional doubling or halving 434 of the ratio of two different SNR[dB] values.

435 The fMSE for dataset $\mathrm{i}$ can be calculated using Equation 5 and is inversely related to the SNR 436 value (Draper et al., 2013).

$437 f M S E_{i}=\frac{1}{1+S N R_{i}}$,

438 The scale of fMSE is between ' 0 ' and ' 1 '. A lower/higher fMSE indicates a clearer/noisier 439 signal of the SSM value. Thus, when the fMSE is ' 0 ', its SSM observation does not include 440 noise. Here, an fMSE of ' 1 ' means there is only noise in its SSM observation. If the fMSE 441 value is lower than 0.5, its SSM observation signal is stronger than its noise.

443 The $\mathrm{R}_{\mathrm{i}}{ }^{2}$ value can be calculated from following equation:

$444 \quad R_{i}^{2}=\frac{1}{1+\frac{1}{S N R_{i}}}$,

445 The $\mathrm{R}_{\mathrm{i}}^{2}$ is different with conventional R-values in terms of its independency (McColl et al., 446 2014). $\mathrm{R}_{\mathrm{i}}{ }^{2}$ does not require a reference dataset as a conventional $\mathrm{R}$ value, which can degrade 447 the value of R owing to random errors in the reference dataset. Details of the TC statistics 448 described above are presented in Gruber et al. (2016). In addition, because $\mathrm{R}_{\mathrm{i}}^{2}$ does not provide 449 a more distinctive perspective than SNR[dB], we focused on the SNR and fMSE results. 


\subsubsection{Taylor diagrams}

452 A Taylor diagram can represent multiple statistics for comparison of different $\mathrm{SSM}_{S A T}$ against

453

454

455

456

457

458

459

460

461

462

$463 \quad S D V=\frac{\sigma_{S M_{S A T}}}{\sigma_{S M_{i n-s i t u}}}$,

$464 E^{2}=\frac{\left(R M S D^{2}-\text { Bias }^{2}\right)}{\sigma^{2} M_{\text {in-situ }}}$, Equations 7 and 8, respectively. the $\operatorname{SSM}_{R E F}$ (e.g., in situ) data on two-dimensional plots. Normalized standard deviation (SDV) indicates the ratio between the $\mathrm{SSM}_{S A T}$ and in situ measurement standard deviations. In the Taylor diagram, the SDV values are shown as radial distance, R-values (Equation 5) with in situ data are shown as an angle in the polar plot, and the in situ observation is shown as a point on the $\mathrm{x}$-axis at $\mathrm{R}=1$ and $\mathrm{SDV}=1$. The centered $\mathrm{RMSD}(\mathrm{E})$ between $\mathrm{SSM}_{S A T}$ and the in situ dataset, which was normalized using the in situ standard deviations, is the distance to this point. E quantifies errors in the pattern variations, whereas SDV provides the relative amplitude and does not include information on bias (Albergel et al., 2012). SDV and E are computed using

466 The E value can be calculated from SDV and R (Equation 9) because they are complementary 467 but not independent (Taylor, 2001). 


\subsubsection{Maximized $R$ method for combining soil moisture datasets}

472 One of the main goals of this research was to determine whether the SMAP product contributes

473

474

475

476

477

478

479

480

481

482

483

484

485

486

487

488

489

490

to better performance of the combined datasets when it is considered as a candidate for combining with multiple SSM products. Combinations of SMAP, ASCAT, and AMSR2 were considered for the final blended product. SMAP and ASCAT, hereafter referred to as SMAP+ASCAT; AMSR2 and SMAP, hereafter referred to as AMSR2+SMAP; and ASCAT and AMSR2, hereafter referred to as ASCAT+AMSR2, were combined using the maximized R method. As mentioned in Section 1, the maximized R method is capable of improving the temporal R-values between combined and reference datasets if the reference value is well chosen. Kim et al. (2015b) suggested that the maximized R method can improve the temporal $\mathrm{R}$-value of certain products with respect to reference values, and determined that the combined dataset is generally superior to those of the individual products. The combined SSM products were calculated by applying a weighting factor $(w)$ with a constrained range of $0-1$ as follows:

$S M_{C}=w \times S S M_{1}+(1-w) \times S S M_{2} \quad(0 \leq w \leq 1)$,

This combination process was only implemented for a given pixel when both parent products were available. Moreover, if the R-value of the combined product in a given location was less than the R-value of one of the parent products, then the parent product with the higher skill was used instead of the combined product. 


$$
R=f(w)=\frac{E\left[\left(\mathbf{S S M}_{\mathbf{C}}-\mu_{S S M_{C}}\right)\left(\mathbf{S S M}_{\mathbf{R E F}}-\mu_{S S M_{R E F}}\right)\right]}{\sigma_{S S M_{C}} \sigma_{S S M_{R E F}}},
$$

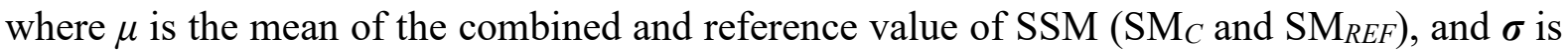
the standard deviation of the combined and reference value of SSM ( $\mathrm{SM}_{C}$ and $\left.\mathrm{SM}_{\mathrm{REF}}\right)$. To combine two different $\mathrm{SSM}$ products (i.e., $\mathrm{SSM}_{1}$ and $\mathrm{SSM}_{2}$ ) from Equation 10 , the systematic differences between the reference SSM and each parent product (i.e., SMAP, ASCAT, and AMSR2) should be removed. Draper et al. (2009) suggested that the normalization of each product against a reference dataset (accomplished using Equation 12), could be used to remove systematic differences:

$$
\mathbf{S S M}_{\mathbf{N O R}}=\left(\mathbf{S S M}_{\mathbf{S A T}}-\mu_{S S M_{R A W}}\right) \times \frac{\sigma_{S S M_{R E F}}}{\sigma_{S S M_{S A T}}}+\mu_{S S M_{R E F}},
$$
where $\mathrm{SSM}_{N O R}$ is the normalized SSM against the reference product. After normalization, Equation 11 was differentiated with respect to $w$ to determine the value of $w$ that optimizes the maximum R-value between $\mathrm{SSM}_{C}$ and $\mathrm{SSM}_{R E F}$. Finally, we obtained $w$ using 
$w=\frac{R_{S S M_{1} \cdot R E F}{ }^{-R_{S S M_{1}} \cdot S M_{2}}{ }^{\times R_{S S M_{2}} \cdot R E F}}{R_{S M_{2} \cdot R E F^{-}} R_{S S M_{1}} \cdot S S M_{2}{ }^{\times R_{S S M_{1}} \cdot R E F^{+}}{ }_{S S M_{1} \cdot R E F}-R_{S S M_{1}} \cdot S M_{2}{ }^{\times R_{S S M_{2}} \cdot R E F}}$,

where $R_{x \cdot y}$ is the correlation coefficient between the two products. In addition, a numerical method was utilized to maximize $\mathrm{R}$ if either parent product showed a negative $\mathrm{R}$-value. In order to find the maximum of a constrained non-linear function, we used the MATLAB function fmincon (http://au.mathworks.com/help/optim/ug/fmincon.html). By setting the constraints (0 $\leq \mathrm{w} \leq 1$ ) and the objective function (Equation 11), the weight factors could be optimized numerically. In total, 157,710 pixels were combined and numerical calculations occurred 5,150, 12,798, and 2,548 times for the SMAP+ASCAT, ASCAT+AMSR2, and AMSR2+SMAP combinations, respectively.

\section{Results and Discussion}

\subsection{Comparison with in situ observations}

The results of the statistical metrics for the comparison of GLDAS SSM, SMAP, ASCAT, AMSR2, and in situ SSM are shown in Table 2 for the period from 2015 to 2016 . The average R-values for all networks were $0.73,0.74,0.64$, and 0.65 for GLDAS, SMAP, ASCAT, and AMSR2, respectively. The average ubRMSD values were $(0.0438,0.0411,0.0625$, and 0.0708$)$ $\mathrm{m}^{3} \mathrm{~m}^{-3}$, and the average bias values were $(0.0035(0.03),-0.0460(0.06), 0.0010(0.04)$, and 
529 the parenthesis indicate the average absolute bias value. In terms of average R-value, GLDAS 530 and SMAP showed better performance than the other products. The highest averaged R-value

531 from SMAP compared with the in situ results were very encouraging; moreover, among all 532 three satellite SSM products, only SMAP had a higher R-value than GLDAS in COSMOS (20 533 of 73), RSMN (17 of 19), SCAN (76 of 1018), SOLSCAPE (3 of 291), and USCRN (49 of 486) 534 networks. In terms of the average ubRMSD, GLDAS and SMAP had the lowest values, with 535 SMAP showing an overall dry bias. AMSR2 had the highest ubRMSD value and an overall wet 536 bias. In addition, because we chose the GLDAS dataset to provide the reference values (which 537 show low ubRMSD, bias, and absolute bias values against in situ observations), the ubRMSD 538 and bias values in the combined products are expected to be greatly improved in relation to the 539 in situ observations. However, many observations of R-values from GLDAS were similar to or 540 less than those of SMAP; therefore, the R-value for the combination of SMAP with other 541 products is expected to be barely improved; perhaps even decreased. Please find details in the 542 discussion in Section 3.3. 
Table 2. Summary of statistical results comparing the different satellite SSM products with ISMN in situ observations.

\begin{tabular}{|c|c|c|c|c|c|c|c|c|c|c|c|c|}
\hline \multirow{2}{*}{ Site name(NOS) } & \multicolumn{3}{|c|}{ GLDAS } & \multicolumn{3}{|c|}{ SMAP } & \multicolumn{3}{|c|}{ ASCAT } & \multicolumn{3}{|c|}{ AMSR2 } \\
\hline & $\mathbf{R}$ & $\operatorname{ubRMSD}\left(\mathbf{m}^{3} \mathbf{m}^{-3}\right)$ & $\operatorname{Bias}\left(m^{3} m^{-3}\right)$ & $\mathbf{R}$ & ubRMSD $\left(\mathbf{m}^{3} \mathbf{m}^{-3}\right)$ & $\operatorname{Bias}\left(\mathbf{m}^{3} \mathbf{m}^{-3}\right)$ & $\mathbf{R}$ & ubRMSD & $\operatorname{Bias}\left(\mathrm{m}^{3} \mathrm{~m}^{-3}\right)$ & $\mathbf{R}$ & ubRMSD $\left(\mathbf{m}^{3} \mathbf{m}^{-3}\right)$ & $\operatorname{Bias}\left(\mathrm{m}^{3} \mathrm{~m}^{-3}\right)$ \\
\hline COSMOS (20) & 0.66 & 0.0446 & 0.0160 & 0.73 & 0.0409 & -0.0276 & 0.66 & 0.0594 & 0.0085 & 0.54 & 0.0683 & 0.0175 \\
\hline REMEDHUS (5) & 0.86 & 0.0315 & 0.0391 & 0.83 & 0.0269 & -0.0383 & 0.79 & 0.0688 & 0.0245 & 0.85 & 0.0661 & 0.1053 \\
\hline RSMN (17) & 0.61 & 0.0493 & 0.0773 & 0.69 & 0.0526 & 0.0516 & 0.60 & 0.0867 & 0.1212 & 0.57 & 0.1039 & 0.1712 \\
\hline SCAN (77) & 0.69 & 0.0461 & 0.0035 & 0.70 & 0.0415 & -0.0490 & 0.61 & 0.0576 & -0.0011 & 0.60 & 0.0653 & 0.0207 \\
\hline SMOSMANIA (5) & 0.83 & 0.0374 & -0.0560 & 0.68 & 0.0346 & -0.1011 & 0.77 & 0.0470 & -0.0625 & 0.78 & 0.0885 & 0.0569 \\
\hline SNOTEL (38) & 0.79 & 0.0597 & -0.0290 & 0.71 & 0.0648 & -0.0864 & 0.75 & 0.0594 & -0.0355 & 0.60 & 0.0710 & -0.0176 \\
\hline SOILSCAPE (3) & 0.69 & 0.0381 & -0.0221 & 0.85 & 0.0282 & -0.0726 & 0.39 & 0.0638 & -0.0560 & 0.64 & 0.0433 & -0.0405 \\
\hline USCRN (49) & 0.71 & 0.0434 & -0.0010 & 0.73 & 0.0392 & -0.0443 & 0.57 & 0.0572 & 0.0092 & 0.65 & 0.0601 & 0.0208 \\
\hline Average & 0.73 & 0.0438 & $0.0035(0.03)$ & 0.74 & 0.0411 & $-0.0460(0.06)$ & 0.64 & 0.0625 & $0.0010(0.04)$ & 0.65 & 0.0708 & $0.0418(0.06)$ \\
\hline
\end{tabular}

*NOS: number of stations

Note: The SWI was considered when the satellite SSM was compared with in situ observations. 


\subsection{Comparison using TC statistics}

548 The in situ-based statistical results provide only limited regional satellite SSM performance 549 and have scale mismatch issues. These limitations can be addressed by employing TC analysis. 550 This enables inspection of global scale satellite-based SSM datasets. In this section, each 551 product was compared using TC metrics. A simple sensitivity analysis was conducted in terms 552 of different VOD ranges because vegetation is one of the most important parameters in the SSM retrieval algorithm (O’Neill et al., 2016). Furthermore, the results were interpreted using land classification datasets to provide the advantages and limitations of using certain satellite products for practical applications at global scale.

\subsubsection{Global trends from TC statistics}

Fig. 3 shows global maps of three different TC metrics (SNR $[d B], \mathrm{R}_{\mathrm{i}}{ }^{2}$, and fMSE) for SMAP, ASCAT, and AMSR2. Similarly, in Fig. 4, the statistical performance of SNR[dB] for three satellite products was calculated and is ranked on the basis of higher value.

The TC results (Fig. 3) indicate that all satellite products have limitations in retrieving SSM in northern Africa, the Middle East, northern Asia, regions of Central Australia, and the western USA; where most of the world's large, bare deserts and arid regions are located. Most of these regions were classified as desert and semi-desert by the BATS model (Fig. 1), had a VOD value $<0.20$, and showed a high average sand fraction value $(49.35 \%)$. These regions are known for high systematic retrieval error because the soil is extremely dry, and microwave-based SSM retrieval systems suffer significant challenges in providing a reading (Dorigo et al., 2010). First, these challenges are associated with problems in estimating the thickness of the emitting layer and the effective temperature (Holmes et al., 2006). Microwave bands of lower frequency (i.e., 
570 L- or C1-bands) penetrate dry soils even deeper and signals from deeper layers; therefore, 571 significant problems arise when SSM is retrieved not only from passive microwave band 572 instruments but also from active microwave band instruments in arid and semi-arid 573 environments (Ulaby et al., 1986; Escorihuela et al., 2009; Wagner et al., 2013). Also, arid 574 regions have very little SSM variation and changes in the SSM signal are often too small to 575 exceed the background noise of the instrument. This adds to difficulties in retrieving SSM 576 information using microwave-frequency observations. However, in the present research, only 5773,211 of 33,850 pixels (total number of desert and semi-desert pixels) were available for 578 investigation of these regions. This means that definitive results can only be obtained after 579 getting more and larger datasets to study in the future. 

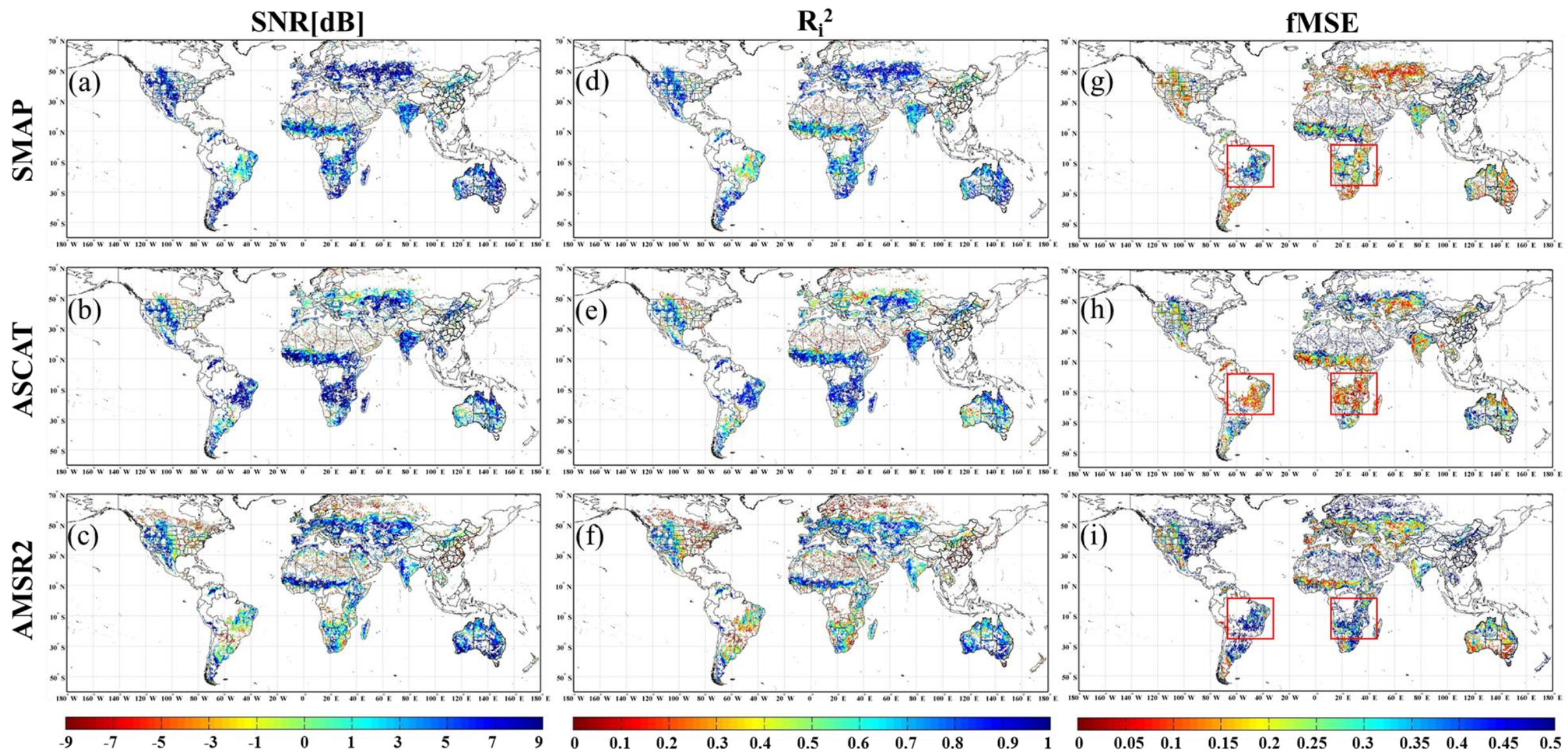

Figure 3. Global maps of the statistical results for the SMAP (first row), ASCAT (second row), and AMSR2 (third row) SSM datasets: (a)-(c) for SNR[dB] estimates, (d)-(f) for $\mathrm{R}_{\mathrm{i}}{ }^{2}$ estimates, and (g)-(i) for fMSE estimates for the period April 2015 to December 2016. The red boxes in (g), (h), and (i) indicate the apparent contrast of fMSE between active and passive products. 


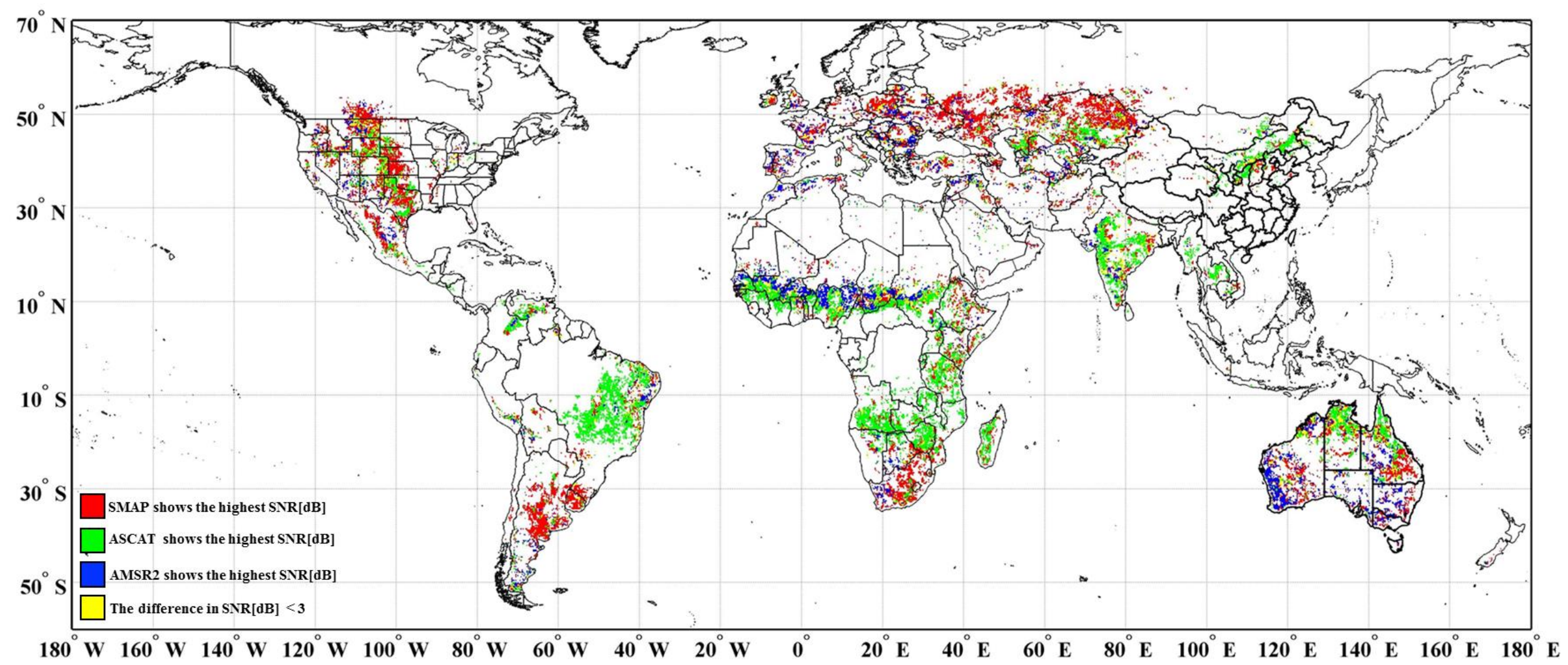

Figure 4. Comparisons, in terms of SNR[dB], among the SMAP, AMSR2, and ASCAT SSM datasets for the period April 2015 to December 2016. The map shows the areas where SMAP (red), ASCAT (green), and AMSR2 (blue) have the highest $588 \mathrm{SNR}[\mathrm{dB}]$ values. The yellow pixels indicate where all three SNR[db] values are similar. The areas where the condition of $\mid \# 1$ $\# 2|<3 \mathrm{db} \&| \# 2-\# 3|<3 \mathrm{db} \&| \# 1-\# 3 \mid<3 \mathrm{db}$ is fulfilled. The white pixels indicate insignificant results $(\mathrm{p} \geq 0.05)$. 
Fig. 5a shows that ASCAT had the lowest number of the best SNR[dB] pixels in these areas, as indicated by the negative SNR[dB] (see the $\mathrm{x}$-axis VOD range of $0.00-0.20$ ). This is a wellknown active sensor issue: they appear to be more sensitive to sub-surface heterogeneities or surface roughness (Wagner et al., 2003; Gruhier et al., 2010; Wagner et al., 2013). Wagner et al. (2013) also indicated that over some desert areas, passive SSM products are recommended for use, particularly over regions for which the value of VOD is $\sim 0.00-0.20$, and the average desert and semi-desert areas account for $82.5 \%$ of the land surface (Figs. 1 and S3).

For the VOD range between 0.00 and 0.10 , the TC statistics for SMAP, ASCAT, and AMSR2 are shown in Fig. 5b (SNR[dB]: 1.57, -1.48 and 0.66), Fig. 5c $\left(\mathrm{R}_{\mathrm{i}}{ }^{2}: 0.56,0.45\right.$, and 0.53), and Fig. 5d (fMSE: 0.44, 0.55, and 0.47). All products showed high fMSE in these regions. Over an extremely dry surface, an active sensor can produce a wet bias from the unpredictable volume scattering from deeper soil layers or scattering from subsurface heterogeneity; as a result, erroneously higher SSM retrievals can be produced. This is supported by previous research indicating that the amount of backscatter decreased when the soil became slightly wet over desert or semi-arid environments (Wagner et al., 2013). Moreover, the dielectric property of quartz, which is significant given the very high sand fractions in desert and semi-desert regions (see Fig. 1 and Fig. S4), can hamper retrieval of SSM by passive satellites (Pan et al., 2016). However, the passive-based datasets showed slightly better performance than did the ASCAT dataset for arid regions. This is apparent in the result of fMSE in Fig. 5d. The average value of the fMSE of ASCAT was $>0.5$ and showed only negative SNR[dB] among all products. This indicates that the ASCAT SSM observations for such regions have higher noise variance than that of the observed SSM signals. 

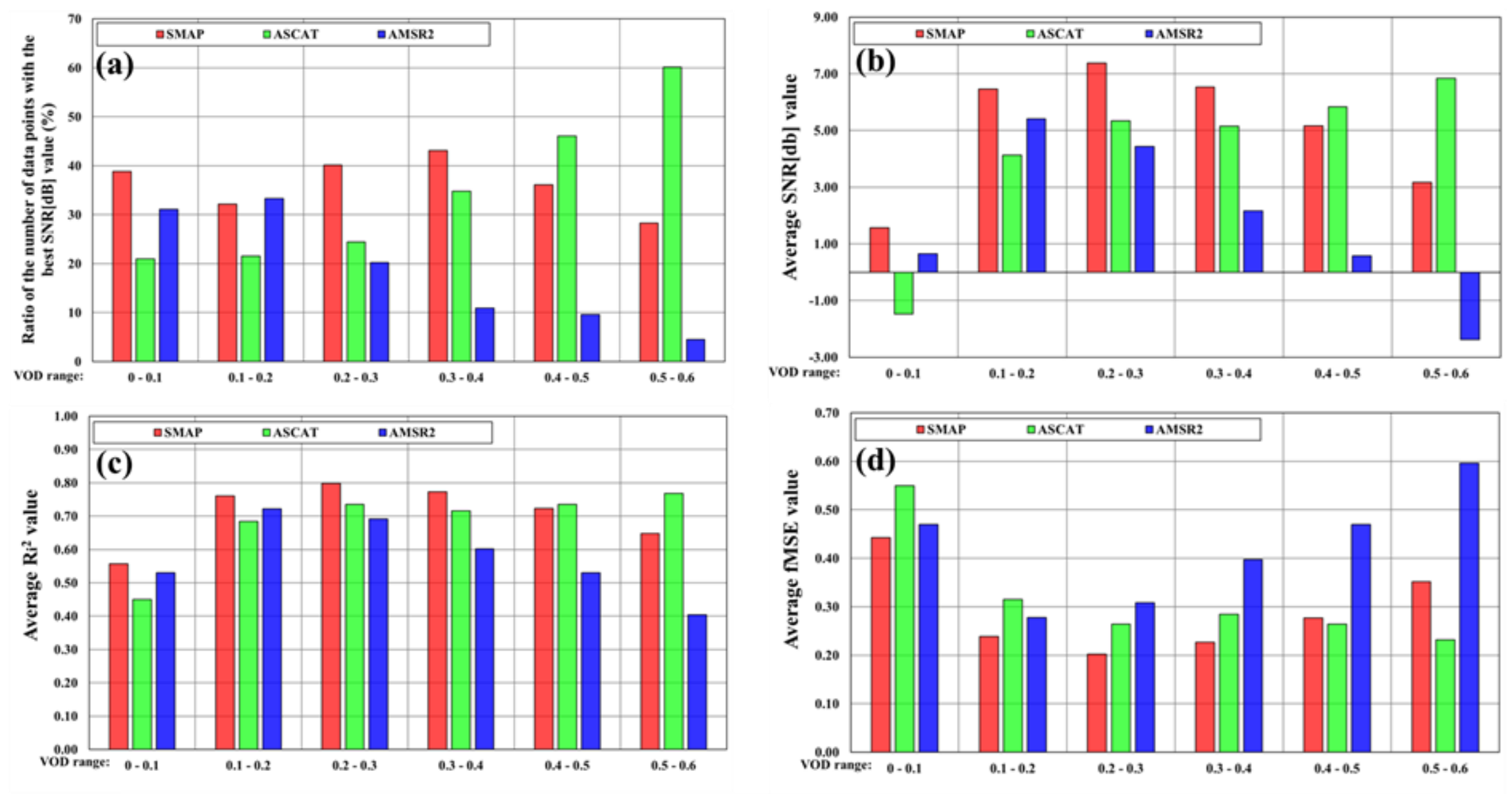

\begin{tabular}{cccc}
\hline VOD range & $0.0-0.1$ & $0.1-0.2$ & $0.2-0.3$ \\
\hline Number of Datasets & 1,199 & 5,003 & 8,860
\end{tabular}

8,860

$0.4-0.5$

$0.5 \cdot 0.6$

Figure 5. Bar graphs showing (a) the percentage of the pixels with the best TC metrics (see Fig. 4) for various satellites 614 for six different ranges of VOD values. (b) Average SNR[dB] for various satellites in terms of six ranges of VOD values. 615 (c) Same as (b) but for $\mathrm{R}_{\mathrm{i}}^{2}$; (d) Same as (b) but for fMSE. 
616 As VOD increased from a sparsely vegetated value $(0.00<$ VOD $<0.20)$ to a moderately 617 vegetated value $(0.20<\mathrm{VOD}<0.40)$, where crop and mixed farming, and tall and short grass are the major surface covers (Fig. 1c), the average SNR[dB] values for ASCAT and SMAP remarkably increased, whereas those for AMSR2 notably decreased after VOD exceeded 0.20. Over the moderately vegetated areas, SMAP had the highest SNR[dB], at 5.16-7.38 (red bars in Fig. 5b). Over more vegetated regions $(0.40<$ VOD $<0.60)$, where more than $76 \%$ of the area was covered by trees (Fig. 1c), ASCAT had the best SNR[dB] (green bars in Fig. 5). These results imply that ASCAT has better ability to reproduce accurate temporal patterns of the SSM than those of passive-based satellite products over densely vegetated areas. Moreover, the apparent contrast of fMSE between active and passive products are shown in the red boxes in Figs. 3 (g)-(i). One of the reasons for this result is that active microwave sensors are known to be less sensitive to surface temperature effects than passive sensors. This is a known characteristic of the instrument; thus, the active sensor can show better performance over widely varying temperature regions. Therefore, ASCAT showed less susceptibility to diurnal surface temperature variation over densely vegetated areas. Our results were consistent with the findings in several previous studies (Scipal et al., 2008b; Dorigo et al., 2010; Al-Yaari et al., 2014b). However, considering alternative technologies, the passive microwave SSM retrievals could be improved if the effective temperature estimates were parameterized (Parinussa et al., 2011).

When two passive products were compared, SMAP showed better results in the statistical 636 metrics for almost all the vegetation ranges. Over densely vegetated regions, the average SNR[dB] from SMAP decreased from 7.38 to 3.17 (red bars in Fig. 5b), and the SNR[dB] from AMSR2 remained $<3$ (blue bars in Fig. 5b). This difference is likely attributable to the operating band. The C-and X-band frequencies of the passive sensors can easily be attenuated 
by vegetation, which makes their measurements relatively insensitive to SSM variability. The lower frequency band of SMAP (i.e., L-band) penetrates vegetation better than the AMSR2 high-frequency bands (i.e., C1-, C2-, and X-bands). Furthermore, during the early morning, both the near-surface temperature change and Faraday rotation effects were at their minimum (Kerr et al., 2001). These conditions aid in the retrieval of SMAP SSM from the passive microwave radiometer at the 06:00 LT overpass time (Le Vine et al., 2000; Jackson et al., 2010). In addition, it is noteworthy that areas with VOD values of more than 0.6 had SSM datasets masked out, meaning that SSM retrieval from dense forests, such as those of the Amazon and Southeast Asia, remains impossible.

When the fMSE values were carefully investigated, as Fig. 5d shows, it became clear that the AMSR2 product should be carefully reviewed before using it for practical applications in densely vegetated areas (VOD $>0.50$ ), as was also apparent from the negative SNR[dB] results in Fig. 5b (average fMSE value $>0.50$ ). This indicates that AMSR2 SSM observations in these regions have higher noise variance than the observed SSM signal variance.

\subsection{Evaluation of combined soil moisture products}

As discussed in Section 3.2, different products showed distinctive performance and error characteristics over land with different properties and in different climate zones. We assumed that the combination of different products would provide complementary abilities that could increase the $\mathrm{R}$ and lower the ubRMSD and bias values. To combine a pair of different SSM products, the maximized R approach was utilized (Section 2.6.3) using the GLDAS products as the reference data set. Table 3 shows the results of the statistical metrics for GLDAS (Table 
663 based on GLDAS (Table 3; third column) against the in situ observations. The datasets were 664 separated into two parts: calibration dataset for 2015, and validation dataset for 2016, to 665 achieve an independent validation process.

666 Except for the R-value results of SMAP, the R-values of combined product AMSR2+ASCAT 667 were improved when compared with the original products alone. This result can be explained 668 by the performance of the reference dataset against in situ observations. Because many in situ observations in GLDAS had lower R-values than in SMAP, the computation of the weights was affected and resulted in calculation of sub-optimal weights. Therefore, the SMAP R-value rarely showed large improvement or even decreased, even after combination with other products. However, these points also imply that SMAP could be utilized to provide reference values to improve the temporal dynamics of GLDAS SSM datasets. In addition, because we chose a reference dataset with low ubRMSD $\left(0.0411 \mathrm{~m}^{3} \mathrm{~m}^{-3}\right)$ and bias $\left(0.0109 \mathrm{~m}^{3} \mathrm{~m}^{-3}\right)$ values against in situ observations, the ubRMSD and bias values in the combined products were 676 greatly improved. 
Table 3. Statistical results comparing GLDAS, different satellite SSM, and combined products with in situ observations.

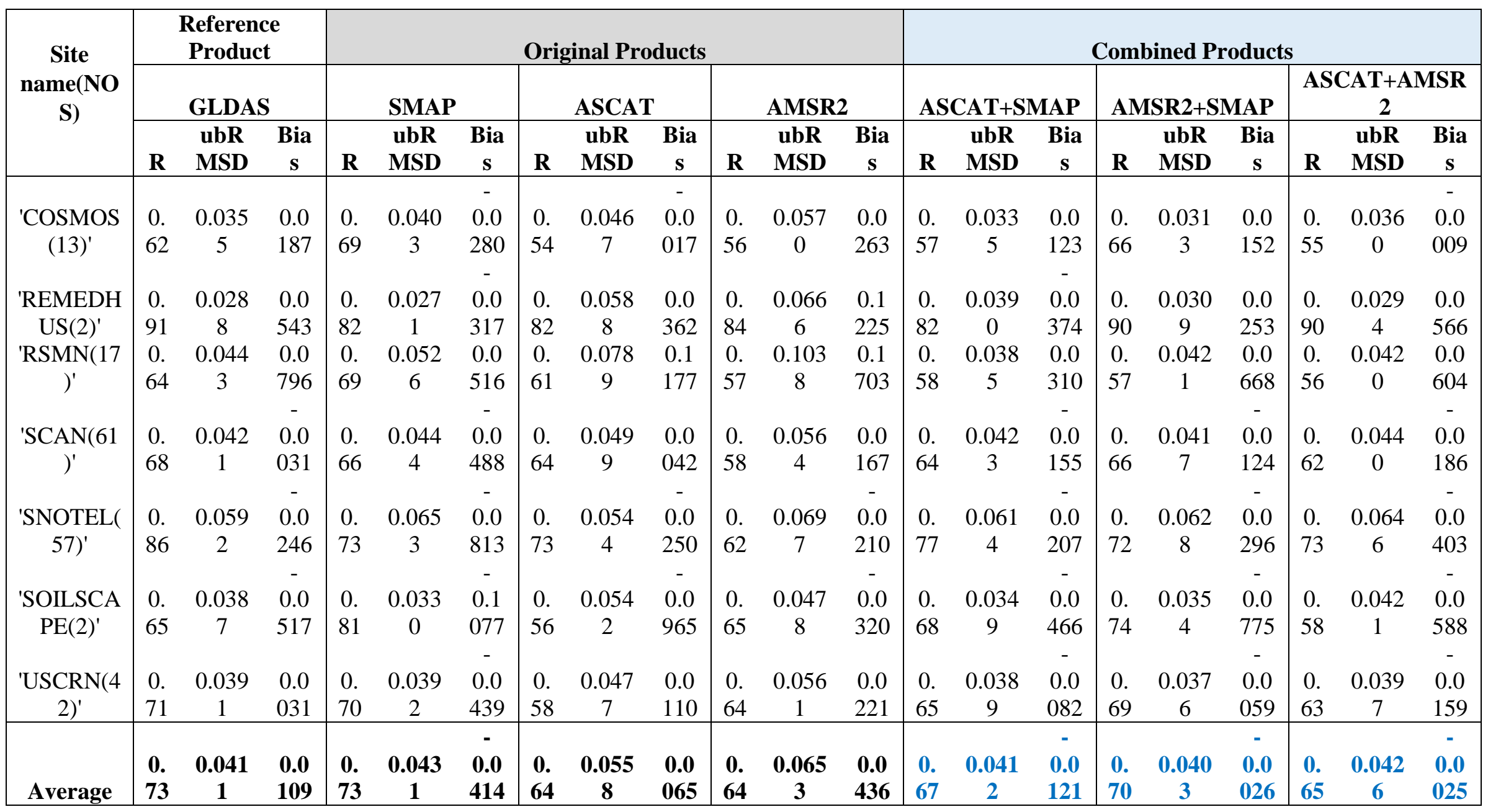




\begin{tabular}{|c|c|c|c|c|c|c|c|c|c|c|c|c|c|c|c|c|c|c|c|c|c|}
\hline \multirow{3}{*}{ Site name(NOS) } & \multirow{2}{*}{\multicolumn{3}{|c|}{$\begin{array}{c}\text { Reference Product } \\
\text { GLDAS } \\
\end{array}$}} & \multicolumn{9}{|c|}{ Original Products } & \multicolumn{9}{|c|}{ Combined Products } \\
\hline & & & & \multicolumn{3}{|c|}{ SMAP } & \multicolumn{3}{|c|}{ ASCAT } & \multicolumn{3}{|c|}{ AMSR2 } & \multicolumn{3}{|c|}{ ASCAT+SMAP } & \multicolumn{3}{|c|}{ AMSR2+SMAP } & \multicolumn{3}{|c|}{ ASCAT+AMSR2 } \\
\hline & $\mathbf{R}$ & ubRMSD & Bias & $\mathbf{R}$ & ubRMSD & Bias & $\mathbf{R}$ & ubRMSD & Bias & $\mathbf{R}$ & ubRMSD & Bias & $\mathbf{R}$ & ubRMSD & Bias & $\mathbf{R}$ & ubRMSD & Bias & $\mathbf{R}$ & ubRMSD & Bias \\
\hline 'COSMOS(13)' & 0.62 & 0.0355 & 0.0187 & 0.69 & 0.0403 & -0.0280 & 0.54 & 0.0467 & -0.0017 & 0.56 & 0.0570 & 0.0263 & 0.57 & 0.0335 & 0.0123 & 0.66 & 0.0313 & 0.0152 & 0.55 & 0.0360 & -0.0009 \\
\hline 'REMEDHUS(2)' & 0.91 & 0.0288 & 0.0543 & 0.82 & 0.0271 & -0.0317 & 0.82 & 0.0588 & 0.0362 & 0.84 & 0.0666 & 0.1225 & 0.82 & 0.0390 & -0.0374 & 0.90 & 0.0309 & 0.0253 & 0.90 & 0.0294 & 0.0566 \\
\hline 'RSMN(17)' & 0.64 & 0.0443 & 0.0796 & 0.69 & 0.0526 & 0.0516 & 0.61 & 0.0789 & 0.1177 & 0.57 & 0.1038 & 0.1703 & 0.58 & 0.0385 & 0.0310 & 0.57 & 0.0421 & 0.0668 & 0.56 & 0.0420 & 0.0604 \\
\hline 'SCAN(61)' & 0.68 & 0.0421 & -0.0031 & 0.66 & 0.0444 & -0.0488 & 0.64 & 0.0499 & 0.0042 & 0.58 & 0.0564 & 0.0167 & 0.64 & 0.0423 & -0.0155 & 0.66 & 0.0417 & -0.0124 & 0.62 & 0.0440 & -0.0186 \\
\hline 'SNOTEL(57)' & 0.86 & 0.0592 & -0.0246 & 0.73 & 0.0653 & -0.0813 & 0.73 & 0.0544 & -0.0250 & 0.62 & 0.0697 & -0.0210 & 0.77 & 0.0614 & -0.0207 & 0.72 & 0.0628 & -0.0296 & 0.73 & 0.0646 & -0.0403 \\
\hline 'SOILSCAPE(2)' & 0.65 & 0.0387 & -0.0517 & 0.81 & 0.0330 & -0.1077 & 0.56 & 0.0542 & -0.0965 & 0.65 & 0.0478 & -0.0320 & 0.68 & 0.0349 & -0.0466 & 0.74 & 0.0354 & -0.0775 & 0.58 & 0.0421 & -0.0588 \\
\hline 'USCRN(42)' & 0.71 & 0.0391 & 0.0031 & 0.70 & 0.0392 & -0.0439 & 0.58 & 0.0477 & 0.0110 & 0.64 & 0.0561 & 0.0221 & 0.65 & 0.0389 & -0.0082 & 0.69 & 0.0376 & -0.0059 & 0.63 & 0.0397 & -0.0159 \\
\hline Average & 0.73 & 0.0411 & 0.0109 & 0.73 & 0.0431 & -0.0414 & 0.64 & 0.0558 & 0.0065 & 0.64 & 0.0653 & 0.0436 & 0.67 & 0.0412 & -0.0121 & 0.70 & 0.0403 & -0.0026 & 0.65 & 0.0426 & -0.0025 \\
\hline
\end{tabular}

*NOS: number of stations

Unit: $\mathrm{m} 3 \mathrm{~m}-3$ 
680

681

682

683

684

685

686

687

688

689

690

691

692

693

694

695

696

697

698

699

700

701

702

703

Fig. 6 presents the box plots of R-values for the parents and combined products for six different VOD ranges worldwide. The red boxes represent the R-values of each original product, and the green and blue boxes indicate combined products. In Fig. 6a, the average R-values of SMAP consistently increased as the VOD ranges increased. When SMAP was combined with ASCAT (i.e., SMAP+ASCAT), increased average R-values for VOD ranges over 0.50 were observed in the combined product. However, for VOD ranges $<0.40$, the R-value of SMAP products were hardly improved by the combination process because ASCAT and AMSR2 showed lower SNR[db] than did SMAP in these regions (Fig. 5). Considering the TC results, in which SMAP showed the best SNR[db] over the VOD range 0.00-0.40 and ASCAT showed the best $\mathrm{SNR}[\mathrm{db}]$ over the VOD range $0.40-0.60$, these results are natural consequences.

As shown in Fig. 6b, the R-values from ASCAT (red boxes) continuously increased as the VOD increased. When ASCAT was combined with SMAP (SMAP+ASCAT; green boxes in Fig. 6b) and AMSR2 (SMAP+AMSR2; blue boxes in Fig. $6 \mathbf{b}$ ), the averaged values of R increased rapidly at VOD less than 0.20 . Moreover, SMAP+ASCAT slightly increased as the VOD increased, before reaching 0.40. ASCAT+AMSR2 (blue boxes in Fig. 6b) did not show improvement for VOD $>0.20$ (green boxes in Fig. 6b). These results indicate that AMSR2 could be utilized to improve the performance of ASCAT over sparsely vegetated areas, and that SMAP is a good choice to improve ASCAT except over densely vegetated areas. These results are well explained by the SNR[db] results as well.

As shown in Fig. 6c, the average R-value of AMSR2 (red boxes) increased for VOD $<0.30$ (0.28-0.67); however, it decreased for VOD > 0.30. In particular, for VOD > 0.40; ASCAT+AMSR2 (blue boxes in Fig. 6c) compensated for the decreasing pattern in average Rvalue from AMSR2 better than AMSR2+SMAP did (green boxes in Fig. 6c). These results suggest that for VOD $>0.40$, ASCAT can be recommended as a strong candidate for 
combination with passive SSM retrieval. However, in the lower VOD range, AMSR2 is a relatively stronger contributor because it improves the temporal dynamics of both ASCAT and SMAP products (blue boxes in Figs. 6a and b). When ASCAT is considered for combination with passive satellite data over densely vegetated areas, it is better to choose a lower frequency (L-band) for SSM retrieval than a higher frequency. The L-band frequency offers the added advantage of being able to take measurements in conditions with denser vegetation than is possible with the C- or X-bands (green boxes versus blue boxes in Fig. 6b).

The results above emphasize that utilizing a variety of SSM datasets has great potential for remedying the shortcomings of individual products in challenging surface regions.

713 Box plots of the ubRMSD and bias are included in Figs. S5 and S6. Because the ubRMSD and

714 bias values were calibrated using a normalization approach, the combined products had 715 ubRMSD values around $0.04\left(\mathrm{~m}^{3} \mathrm{~m}^{-3}\right)$ and bias values around $0.01\left(\mathrm{~m}^{3} \mathrm{~m}^{-3}\right)$. 

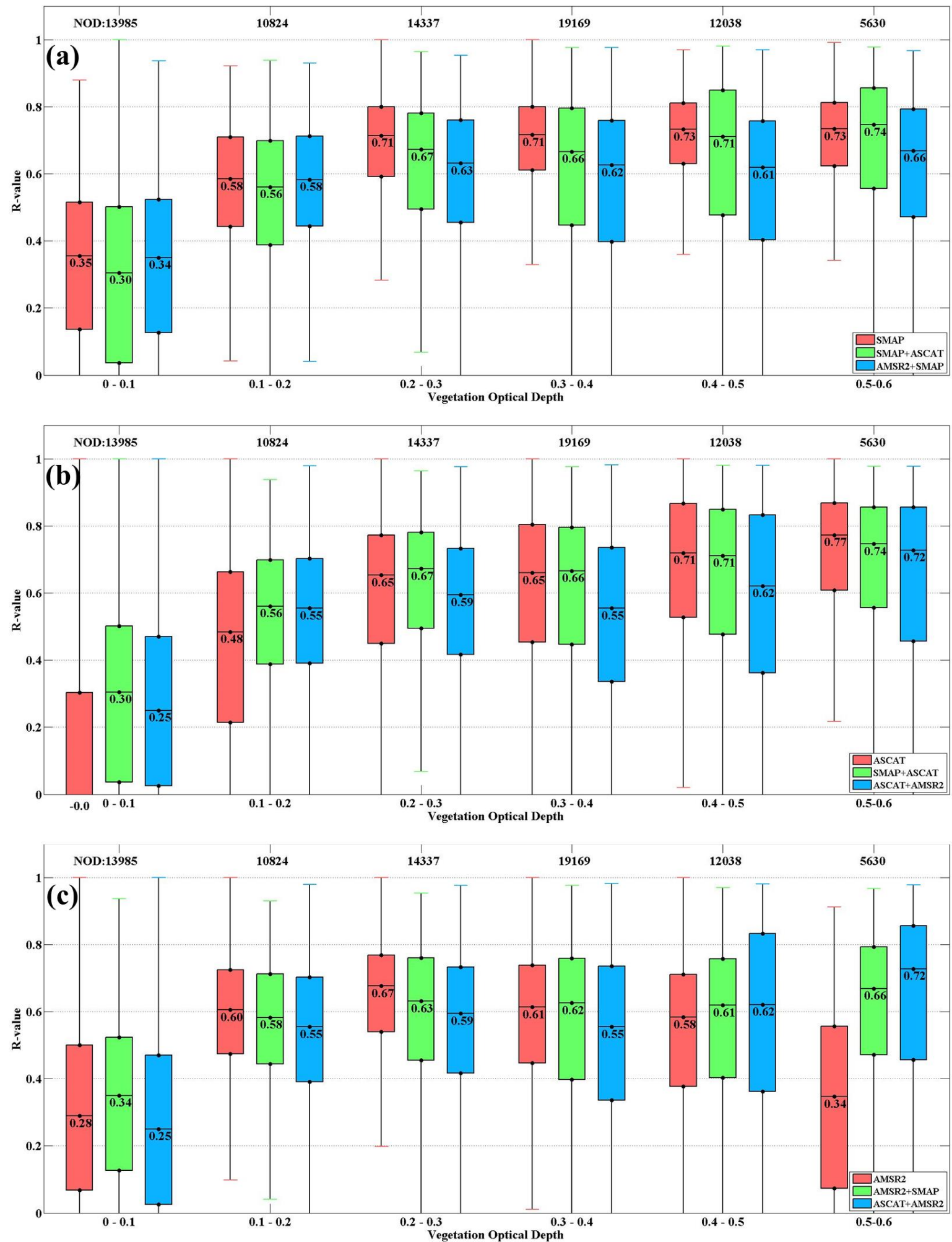

717 Figure 6. Box plots of R-values at different VOD ranges for original products 718 (red boxes) and combined products (green or blue boxes). The number of datasets 719 (NOD) for each VOD bin appears above each box plot. 
Fig. 7 presents two Taylor diagrams, illustrating the statistical comparison of the original and the combined products against in situ observations from each ISMN in 2016. The temporal variability in the original products is demonstrated by the SDV value results. In Fig. 7(a), the SDV values of the original SMAP, ASCAT, and AMSR2 products, represented by red, green, and blue symbols in the figure, are scattered widely in the SDV range 0.4-2.3. In Fig. 7(b), the SDV values of the combined SMAP+ASCAT, AMSR2+SMAP, and ASCAT+AMSR2 products, represented by red, green, and blue symbols in the figure, are gathered near the SDV range 1; straight lines with red, green, and blue colors indicate the average R-values for each product. The SDV value is the ratio between the $\mathrm{SM}_{S A T}$ and $\mathrm{SM}_{I N}$ SITU standard deviations. This statistic indicates that the variability from ground observation is lower than that of the original and combined products if the SDV is $<1$, and vice versa. Moreover, the combined product SDV values are more tightly clustered than the original SDV values; most values are close to ' 1 '. This means that for the products showing temporal variation similar to that of the in situ observations, the combined reproduced lower bias SSM information than the other original products. As we discussed in Section 3.3, the maximized R method highly depends on the performance of the reference values with in situ observations. We utilized the GLDAS datasets that showed better R-values than ASCAT and AMSR2 datasets, but similar or smaller R-values than SMAP datasets. However, the GLDAS datasets showed better results of ubRMSD and a higher absolute bias than all three products against in situ observations (Table 3). For these reasons, ASCAT and AMSR2 could be improved by SMAP at all sites (straight lines in Fig. 7). Unsurprisingly, the R-value of SMAP hardly improved because SMAP showed a better performance against in situ observations than the reference value. However, ubRMSD and bias highly improved because ubRMSD and bias of the reference datasets were closer to zero compared to in situ observations (SDV values in Fig. 7). These results emphasize that SMAP 
744 can be utilized as a reference value for combining the two different datasets to improve the 745 temporal pattern of SSM for satellite-based datasets as well as the model SSM datasets.

746 However, GLDAS datasets are recommended as the reference value to reduce the ubRMSD 747 and bias value. 


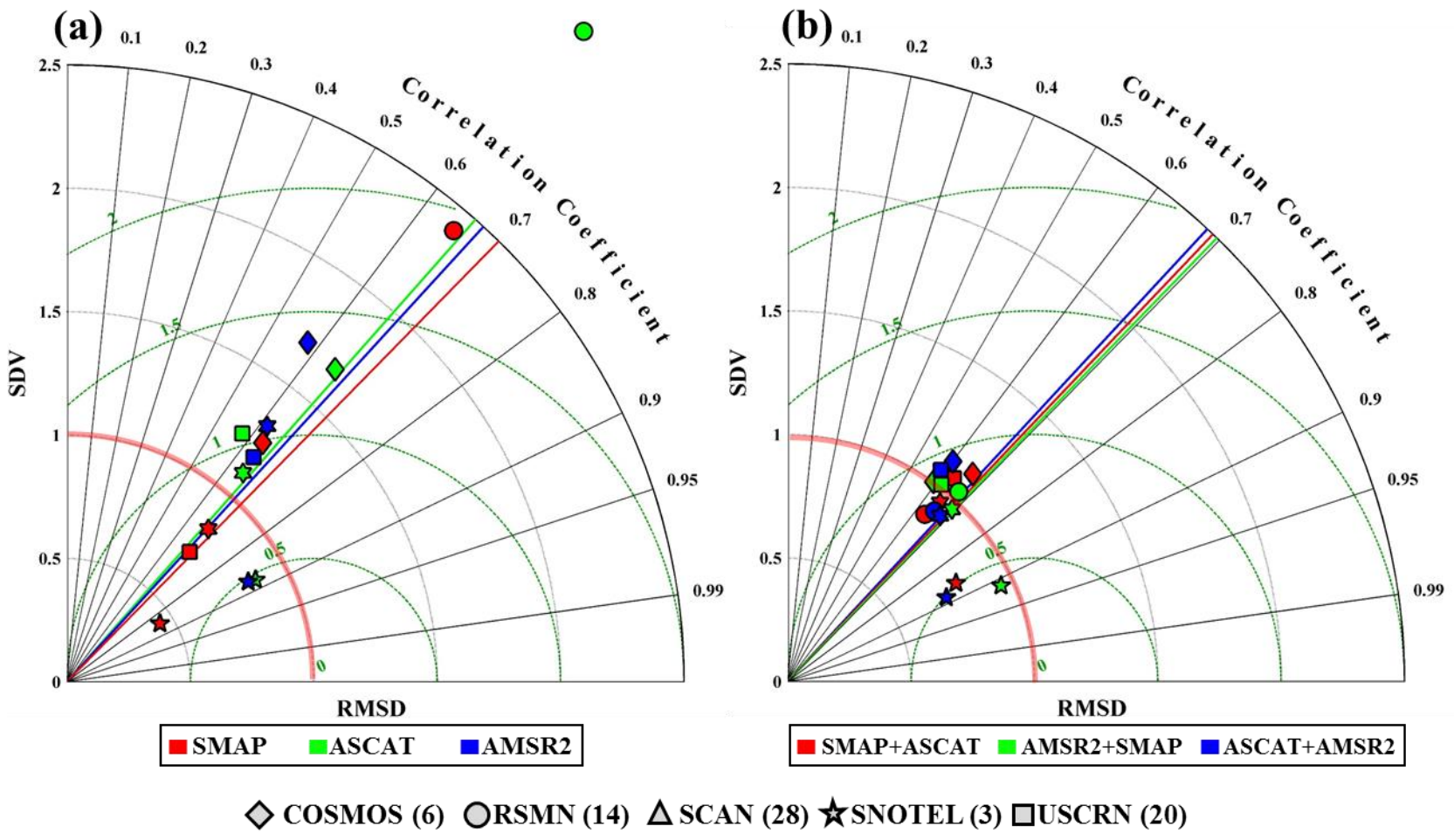

749 Figure 7. (a) Taylor diagram showing the statistical comparisons of the individual satellite products (SWI values from SMAP, ASCAT, or AMSR2) with in situ observations for five different soil moisture networks in 2016. Red indicates the SWI product of SMAP, green indicates the SWI product of ASCAT, and blue 753 indicates the SWI product of AMSR2. Strait lines with red, green, and blue colors 754 indicate the average R-value of each product. (b) same as (a) but Red indicates 755 the SMAP+ASCAT product, green indicates the AMSR2+SMAP product, and 756 blue indicate the ASCAT+AMSR2 product. Each symbol indicates different sites; 757 Diamonds: COSMOS, Circles: RSMN, Triangles: SCAN, Stars: SNOTEL, 758 Rectangles: USCRN. 


\section{Conclusions}

760

761

762

763

764

765

766

767

768

769

770

771

772

773

774

775

776

777

778

779

780

781

In the present study, we investigated the widely used (ASCAT and AMSR2), and a relatively new (SMAP), satellite-based SSM datasets from active and passive microwave sensors and combined them to evaluate the performance of each combined product. First, we compared ASCAT, AMSR2, and SMAP SSM retrievals using in situ observations from 213 stations worldwide. These products were evaluated considering the degree of vegetation and surface properties using TC statistics. Second, we combined three products using the maximized R method, which can be used to maximize the temporal correlation coefficient of the combined products. The GLDAS dataset was used assuming that it had the highest data quality for use with the maximize R method. Finally, we evaluated the performances of the combined products, focusing on the SMAP for the combination process. The major findings of this study are given in the following points.

1. The validation results of all satellite-based SSM products and the GLDAS dataset compared with in situ observations showed that SMAP had the strongest agreements with the temporal dynamic of SSM. SMAP had an average R-value of 0.74 along with a low value of ubRMSD $\left(0.0411 \mathrm{~m}^{3} \mathrm{~m}^{-3}\right)$ and dry bias $\left(-0.0460 \mathrm{~m}^{3} \mathrm{~m}^{-3}\right)$. In comparison, AMSR2 had a wet bias on average $\left(0.0418 \mathrm{~m}^{3} \mathrm{~m}^{-3}\right)$. ASCAT had the least bias and absolute bias $\left(0.0010 \mathrm{~m}^{3} \mathrm{~m}^{-3}\right.$ and 0.04 $\mathrm{m}^{3} \mathrm{~m}^{-3}$ ) among all the satellite products. In addition, AMSR2 had the highest ubRMSD among all products $\left(0.0708 \mathrm{~m}^{3} \mathrm{~m}^{-3}\right)$, which suggests special care be taken in using the AMSR2 product for certain applications.

2. When all satellite products were investigated on the basis of TC statistics on a global scale, it was difficult to retrieve SSM from certain regions of northern Africa, the Middle East, northern Asia, Central Australia, and the western USA. These regions are mostly arid, with 
$82.5 \%$ of the land surface either desert or semi-desert. In particular, ASCAT showed only negative $\mathrm{SNR}[\mathrm{dB}]$ and the highest $\mathrm{fMSE}$ among all products.

3. Over the moderately vegetated areas (VOD range $0.10-0.40$ ), the average SNR[dB] of all products increased significantly compared to that over low- and high-vegetated areas. Although the $\mathrm{SNR}[\mathrm{dB}]$ from ASCAT increased as the VOD increased, the SNR[dB] from SMAP decreased slightly, and the SNR[dB] from AMSR2 decreased more rapidly. Furthermore, when VOD $<0.40$, SMAP had the best SNR $[\mathrm{dB}]$ among all products.

4. Over densely vegetated areas (VOD range 0.40-0.60), ASCAT showed higher SNR[dB] than other products. In contrast, AMSR2 showed only negative $\mathrm{SNR}[\mathrm{dB}]$ and the highest $\mathrm{fMSE}$ among all products.

5. Over the highly vegetated regions (VOD > 0.50) ASCAT performed better, especially when combined with SMAP, which increased the temporal variability of the SSM. This indicates that SSM retrieved using an active microwave sensor has the potential to enhance passive microwave sensor products. In particular, the accuracy of temporal variability from SMAP+ASCAT tended to be better than that in other combined products.

6. SMAP showed good performance when combined with other products, which improved its accuracy in reproducing SSM temporal variability over the sparsely- and moderately-vegetated areas. This suggests that SMAP is a strong candidate for combination with several satellitebased SSM products except over the densely-vegetated regions.

7. The combined products from different satellite-based SSM datasets demonstrated the possibility of overcoming the limitations of individual products in challenging regions. Hence, this work contributes to the improvement of the application of satellite-based SSM in various fields such as NWP, agriculture and forest management, dust outbreaks, water resource and 
irrigation management, and many other surface processes.

806

In the future, study of various correction methods such as cumulative distribution function matching, linear regression correction, and the time-varying weight approach will lead to better performance of the combined products. Also, we used the original version of the SMAP SSM dataset, and its SSM retrieval algorithms will be improved in the near future by field campaigns such as the SMAP Validation Experiment. Especially, different ASCAT SSM products such as the time series products distributed by H-SAF may show better quality than the NRT data found in the EUMETSAT archive. These datasets are expected to be significantly improved in the upcoming product release. Moreover, use of the improved datasets of the parent products provides potential for the combination products to be improved as well.

All satellite products currently improve rapidly when spurred by positive competition; thus, the new mission, SMAP, has considerable potential for being complemented with existing satellite SSM products. In addition, many possibilities remain for improving AMSR2 SSM retrieval because the AMSR2 LPRM SSM products are expected to be much improved through enhanced versions before the final version was released.

The updated and alternate choice for satellite-based SSM and re-analysis datasets can be utilized in future research to provide a better understanding of operational hydrological investigations and to improve combined active/passive satellite products.

\section{Acknowledgements}

The authors thank the teams from NASA, ESA, and JAXA for making their datasets publicly 
available.

828 Global Land Data Assimilation System (GLDAS) data used in this study were acquired as part 829 of the mission of NASA's Earth Science Division and were archived and distributed by the 830 Goddard Earth Sciences (GES) Data and Information Services Center (DISC) 831 (http://disc.sci.gsfc.nasa.gov/). The authors would like to acknowledge the ISMN database service for providing access to the in situ soil moisture observations.

This work was supported by the National Research Foundation of Korea (NRF) grant funded by the Korea government (MSIP) (NRF-2016R1A2B4008312). This research was supported by Space Core Technology Development Program through the National Research Foundation of Korea (NRF) funded by the Ministry of Science, ICT, and Future Planning (NRF2014M1A3A3A02034789).

Wolfgang Wagner thanks the EUMETSAT Satellite Application Facility on Support to Operational Hydrology and Water Management (HSAF) and the ESA Climate Change Initiative (CCI) for their funding support.

\section{References}

Albergel, C., De Rosnay, P., Gruhier, C., Muñoz-Sabater, J., Hasenauer, S., Isaksen, L., ... \&

Wagner, W. (2012). Evaluation of remotely sensed and modelled soil moisture products using global ground-based in situ observations. Remote Sensing of Environment, 118, 215-226, doi:10.1016/j.rse.2011.11.017

Albergel, C., Rüdiger, C., Carrer, D., Calvet, J. C., Fritz, N., Naeimi, V., ... \& Hasenauer, S. (2009). An evaluation of ASCAT surface soil moisture products with in-situ observations in 
849 Southwestern France. Hydrology and Earth System Sciences, 13(2), 115-124, doi:10.5194/hessd-5-2221-2008

Albergel, C., Rüdiger, C., Pellarin, T., Calvet, J. C., Fritz, N., Froissard, F., ... \& Martin, E. (2008). From near-surface to root-zone soil moisture using an exponential filter: an assessment of the method based on in-situ observations and model simulations. Hydrology and Earth System Sciences Discussions, 12, 1323-1337, doi:10.5194/hessd-5-1603-2008

Al Bitar, A., Leroux, D., Kerr, Y. H., Merlin, O., Richaume, P., Sahoo, A., \& Wood, E. F. (2012). Evaluation of SMOS soil moisture products over continental US using the SCAN/SNOTEL network. IEEE Transactions on Geoscience and Remote Sensing, 50(5), 1572-1586, doi:10.1109/tgrs.2012.2186581

Al-Yaari, A., Wigneron, J. P., Ducharne, A., Kerr, Y. H., Wagner, W., De Lannoy, G., Reichle, R., Al Bitar, A., Dorigo, W., Richaume, P., \& Mialon, A. (2014b). Global-scale comparison of passive (SMOS) and active (ASCAT) satellite based microwave soil moisture retrievals with soil moisture simulations (MERRA-Land). Remote Sensing of Environment, 152, 614-626, doi:10.1016/j.rse.2014.07.013

Al-Yaari, A., Wigneron, J. P., Ducharne, A., Kerr, Y., De Rosnay, P., De Jeu, R., Govind, A., 865 Al Bitar, A., Albergel, C., Munoz-Sabater, J., Richaume, P., \& Mialon, A. (2014a). Global-scale 866 evaluation of two satellite-based passive microwave soil moisture data sets (SMOS and AMSRE) with respect to Land Data Assimilation System estimates. Remote Sensing of Environment, 149, 181-195, doi:10.1016/j.rse.2014.04.006

Al-Yaari, A., Wigneron, J. P., Kerr, Y., Rodriguez-Fernandez, N., O'Neill, P. E., Jackson, T. 870 J., ... \& Walker, J. P. (2017). Evaluating soil moisture retrievals from ESA's SMOS and NASA's 
doi:10.1016/j.rse.2017.03.010

Bolten, J. D., Crow, W. T., Zhan, X., Jackson, T. J., \& Reynolds C.A. (2010). Evaluating the utility of remotely sensed soil moisture retrievals for operational agricultural drought monitoring. Selected Topics in Applied Earth Observations and Remote Sensing, IEEE Journal of, 3(1), 57-66. doi:10.1109/jstars.2009.2037163, doi:10.1109/jstars.2009.2037163

Brocca, L., Ciabatta, L., Massari, C., Camici, S., \& Tarpanelli, A. (2017). Soil Moisture for Hydrological Applications: Open Questions and New Opportunities. Water, 9(2), 140, doi:10.3390/w9020140

Brocca, L., Hasenauer, S., Lacava, T., Melone, F., Moramarco, T., Wagner, W., Matgen, P., Martinez-Fernandez, J., Llorens, P., Latron, J., Martin, C., \& Bittelli, M. (2011). Soil moisture estimation through ASCAT and AMSR-E sensors: An intercomparison and validation study across Europe. Remote Sensing of Environment, 115(12), 3390-3408, doi:10.1016/j.rse.2011.08.003

Brocca, L., Melone, F., Moramarco, T., \& Morbidelli, R. (2009). Soil moisture temporal stability over experimental areas in Central Italy. Geoderma, 148(3), 364-374, doi:10.1016/j.geoderma.2008.11.004

Brocca, L., Melone, F., Moramarco, T., Wagner, W., Naeimi, V., Bartalis, Z., \& Hasenauer, S. (2010). Improving runoff prediction through the assimilation of the ASCAT soil moisture product. Hydrology and Earth System Sciences, 14(10), 1881-1893, doi:10.5194/hess-14-18812010

Brocca, L., Morbidelli, R., Melone, F., \& Moramarco, T. (2007). Soil moisture spatial variability in experimental areas of central Italy. Journal of Hydrology, 333(2), 356-373, doi:10.1016/j.jhydrol.2006.09.004 
S. H. (2017). A comparative study of the SMAP passive soil moisture product with existing satellite-based soil moisture products. IEEE Transactions on Geoscience and Remote Sensing, 55(5), 2959-2971, doi:10.1109/tgrs.2017.2656859 retrievals and GLDAS simulations against observations of a soil moisture network on the central Tibetan Plateau. Journal of Geophysical Research: Atmospheres, 118(10), 4466-4475, 902 doi:10.1002/jgrd.50301

Cho, E., Su, C. H., Ryu, D., Kim, H., \& Choi, M. (2017). Does AMSR2 produce better soil 904 moisture retrievals than AMSR-E over Australia?. Remote Sensing of Environment, 188, 95905 105, doi:10.1016/j.rse.2016.10.050

Colliander, A., Jackson, T. J., Bindlish, R., Chan, S., Das, N., Kim, S. B., ... \& Asanuma, J. 907 (2017). Validation of SMAP surface soil moisture products with core validation sites. Remote Sensing of Environment, 191, 215-231. and reconstruction of FY-3B/MWRI soil moisture using an artificial neural network based on reconstructed MODIS optical products over the Tibetan Plateau. Journal of Hydrology, 543, 242-254, doi:10.1016/j.jhydrol.2016.10.005

de Nijs, A. H., Parinussa, R. M., de Jeu, R. A., Schellekens, J., \& Holmes, T. R. (2015). A 914 methodology to determine radio-frequency interference in AMSR2 observations. IEEE 915 Transactions on Geoscience and Remote Sensing, 53(9), 5148-5159, 916 doi:10.1109/tgrs.2015.2417653 
918 Goodge, G. (2013). US Climate Reference Network after one decade of operations: Status and assessment. Bulletin of the American Meteorological Society, 94(4), 485-498, doi:10.1175/bams-d-12-00170.1

Dickinson, R. E. (1984). Modeling evapotranspiration for three-dimensional global climate models. Climate processes and climate sensitivity, 58-72, doi:10.1029/gm029p0058 community climate model. Technical report, doi:10.1002/0470848944.hsa217 transfer scheme (BATS) version 1e as coupled to the NCAR community climate model. National Center for Atmospheric Research, Climate and Global Dynamics Division, 928 doi:10.1002/0470848944.hsa217

Dorigo, W. A., Gruber, A., De Jeu, R. A. M., Wagner, W., Stacke, T., Loew, A., Albergal, C., 930 Brocca, L., Chung, D., Parinussa, R.M., \& Kidd, R. (2015). Evaluation of the ESA CCI soil moisture product using ground-based observations. Remote Sensing of Environment, 162, 380395, doi:10.1016/j.rse.2014.07.023

Dorigo, W. A., Scipal, K., Parinussa, R. M., Liu, Y. Y., Wagner, W., De Jeu, R. A. M., \& 934 Naeimi, V. (2010). Error characterisation of global active and passive microwave soil moisture data sets. Hydrology and Earth System Sciences, 14(12), 2605-2616, doi:10.5194/hess-14936 $2605-2010$ 
940 Dorigo, W. A., Wagner, W., Hohensinn, R., Hahn, S., Paulik, C., Xaver, A., ... \& Robock, A. 941 (2011). The International Soil Moisture Network: a data hosting facility for global in situ soil 942 moisture measurements. Hydrology and Earth System Sciences, 15(5), 1675-1698, 943 doi:10.5194/hessd-8-1609-2011

944 Dorigo, W. A., Xaver, A., Vreugdenhil, M., Gruber, A., Hegyiová, A., Sanchis-Dufau, A. 945 D., ... Drusch, M. (2013). Global automated quality control of in situ soil moisture data from 946 the International Soil Moisture Network. Vadose Zone Journal, 12(3). doi: 947 http://dx.doi.org/10.2136/vzj2012.0097

948 Draper, C. S., Reichle, R. H., De Lannoy, G. J. M., \& Liu, Q. (2012). Assimilation of passive 949 and active microwave soil moisture retrievals. Geophysical Research Letters, 39(4), 950 doi:10.1029/2011GL050655.

951

Draper, C. S., Reichle, R., de Jeu, R., Naeimi, V., Parinussa, R., \& Wagner, W. (2013).

952

953

954

955

956

957

958

959

960

961

962

Estimating root mean square errors in remotely sensed soil moisture over continental scale domains. Remote Sensing of Environment, 137, 288-298, doi:10.1016/j.rse.2013.06.013

Dorigo, W. A., Scipal, K., Parinussa, R. M., Liu, Y. Y., Wagner, W., De Jeu, R. A., \& Naeimi, V. (2010). Error characterisation of global active and passive microwave soil moisture data sets. Hydrology and Earth System Sciences, 14(12), 2605, doi:10.5194/hessd-7-5621-2010

Draper, C. S., Walker, J. P., Steinle, P. J., de Jeu, R. A. M., \& Holmes, T. R. H. (2009). An evaluation of AMSR-E derived soil moisture over Australia. Remote Sensing of Environment, 113(4), 703-710, doi:10.1016/j.rse.2008.11.011

Entekhabi, D., Njoku, E. G., O'Neill, P. E., Kellogg, K. H., Crow, W. T., Edelstein, W. N., ... \& Kimball, J. (2010). The soil moisture active passive (SMAP) mission. Proceedings of the IEEE, 98(5), 704-716, doi:10.1109/jproc.2010.2043918 

sampling depth of L-band radiometry: A case study. Remote Sensing of Environment, 114(5), 995-1001, doi: 10.1016/j.rse.2009.12.011

Famiglietti, J. S., Devereaux, J. A., Laymon, C. A., Tsegaye, T., Houser, P. R., Jackson, T. J., 967 \& Oevelen, P. V. (1999). Ground-based investigation of soil moisture variability within remote 968 sensing footprints during the Southern Great Plains 1997 (SGP97). Hydrology Experiment. Water Resources Research, 35(6), 1839-1851, doi:10.1029/1999wr900047

FAO/IIASA/ISRIC/ISSCAS/JRC. (2009). Harmonized World Soil Database (version 1.1).

Ford, T. W., Harris, E., \& Quiring, S. M. (2014). Estimating root zone soil moisture using near-surface observations from SMOS. Hydrology and Earth System Sciences, 18(1), 139-154, doi:10.5194/hessd-10-8325-2013

Griesfeller, A., Lahoz, W. A., de Jeu, R. A. M., Dorigo, W., Haugen, L. E., Svendby, T. M.,

\& Wagner, W. (2016). Evaluation of satellite soil moisture products over Norway using groundbased observations. International Journal of Applied Earth Observation and Geoinformation, 45, 155-164, doi:10.1016/j.jag.2015.04.016

Gruber, A., Su, C. H., Zwieback, S., Crow, W., Dorigo, W., \& Wagner, W. (2016). Recent 979 advances in (soil moisture) triple collocation analysis. International Journal of Applied Earth 
Hornbuckle, B. K., \& England, A. W. (2005). Diurnal variation of vertical temperature gradients within a field of maize: Implications for satellite microwave radiometry. IEEE

Houser, P. R., Shuttleworth, W. J., Famiglietti, J. S., Gupta, H. V., Syed, K. H., \& Goodrich,

D. C. (1998). Integration of soil moisture remote sensing and hydrologic modeling using data assimilation. Water Resources Research, 34(12), 3405-3420, doi:10.1029/1998WR900001

D. C., Moran, M. S., \& Du, J. (2010). Validation of advanced microwave scanning radiometer soil moisture products. Geoscience and Remote Sensing, IEEE Transactions on, 48(12), 42564272, doi:10.1109/TGRS.2010.2051035 2013), Melbourne, Australia, (pp. 831-834), doi:10.1109/IGARSS.2013.6721287 E. (2010). The SMOS mission: New tool for monitoring key elements of the global water cycle. Proceedings of the IEEE, 98(5), 666-687, doi:10.1109/jproc.2010.2043032 (2001). Soil moisture retrieval from space: The Soil Moisture and Ocean Salinity (SMOS) mission. IEEE transactions on Geoscience and remote sensing, 39(8), 1729-1735, doi: 
Kim, H., \& Choi, M. (2015). Impact of soil moisture on dust outbreaks in East Asia: Using satellite and assimilation data. Geophysical Research Letters, 42(8), 2789-2796, doi:10.1002/2015g1063325

Kim, H., Zohaib, M., Cho, E., Kerr, Y. H., \& Choi, M. (2017). Development and Assessment of the Sand Dust Prediction Model by Utilizing Microwave-Based Satellite Soil Moisture and Reanalysis Datasets in East Asian Desert Areas. Advances in Meteorology, 2017, doi:10.1155/2017/1917372

Kim, S., Liu, Y. Y., Johnson, F. M., Parinussa, R. M., \& Sharma, A. (2015a). A global comparison of alternate AMSR2 soil moisture products: Why do they differ? Remote Sensing of Environment, 161, 43-62, doi:10.1016/j.rse.2015.02.002

Kim, S., Parinussa, R. M., Liu, Y. Y., Johnson, F. M., \& Sharma, A. (2015b). A framework for combining multiple soil moisture retrievals based on maximizing temporal correlation. Geophysical Research Letters, 42(16), 6662-6670, doi:10.1002/2015GL064981

Kim, S., Parinussa, R. M., Liu, Y. Y., Johnson F. M., \& Sharma, A. (2016). Merging Alternate Remotely-Sensed Soil Moisture Retrievals Using a Non-Static Model Combination Approach. Remote Sensing, doi:10.3390/rs8060518

Konings, A. G., \& Gentine, P. (2017). Global variations in ecosystem-scale isohydricity. Global Change Biology, 23(2), 891-905, doi:10.1111/gcb.13389

Konings, A. G., Entekhabi, D., Chan, S. K., \& Njoku, E. G. (2011). Effect of radiative transfer uncertainty on L-band radiometric soil moisture retrieval. IEEE Transactions on Geoscience and Remote Sensing, 49(7), 2686-2698, doi:10.1109/TGRS.2011.2105495

Koster, R. D., Guo, Z., Yang, R., Dirmeyer, P. A., Mitchell, K., \& Puma, M. J. (2009). On 
the nature of soil moisture in land surface models. Journal of Climate, 22(16), 4322-4335, doi:10.1175/2009JCLI2832.1

\section{Lakshmi, V. (2000). A simple surface temperature assimilation scheme for use in land surface} models. Water resources research, 36(12), 3687-3700.

Le Vine, D. M., \& Abraham, S. A. J. I. (2000). Faraday rotation and passive microwave remote sensing of soil moisture from space. Microwave Radiometry Remote Sensing Earth's Surface Atmosphere, 89-96.

Leroux, D. J., Kerr, Y. H., Al Bitar, A., Bindlish, R., Jackson, T. J., Berthelot, B., \& Portet, G. (2014). Comparison between SMOS, VUA, ASCAT, and ECMWF soil moisture products over four watersheds in US. Geoscience and Remote Sensing, IEEE Transactions on, 52(3), 1562-1571, doi:10.1109/TGRS.2013.2252468

Liang, X., Lettenmaier, D. P., Wood, E. F., \& Burges, S. J. (1994). A simple hydrologically based model of land surface water and energy fluxes for general circulation models. Journal of Geophysical Research: Atmospheres, 99(D7), 14415-14428, doi:10.1029/94jd00483

Liu, Y. Y., Dorigo, W. A., Parinussa, R. M., de Jeu, R. A., Wagner, W., McCabe, M. F., Evans, J. P., \& Van Dijk, A. I. J. M. (2012). Trend-preserving blending of passive and active microwave soil moisture retrievals. Remote Sensing of Environment, 123, 280-297, doi:10.1016/j.rse.2012.03.014

Liu, Y. Y., Parinussa, R. M., Dorigo, W. A., De Jeu, R. A. M., Wagner, W., Van Dijk, A. I. J. M., McCabe, M. F., \& Evans, J. P. (2011). Developing an improved soil moisture data set by blending passive and active microwave satellite-based retrievals. Hydrology and Earth System Sciences, 15(2), 425-436, doi:10.5194/hess-15-425-2011 

(2012). ASCAT Surface State Flag (SSF): Extracting information on surface freeze/thaw

1054

1055

1056

1057

1058

1059

1060

1061

1062

1063

1064

1065

1066

1067

1068

1069

1070 1071 Ibaraki, Japan.

1072

1073

1074

conditions from backscatter data using an empirical threshold-analysis algorithm. Geoscience and Remote Sensing, IEEE Transactions on, 50(7), 2566-2582, doi:10.1109/TGRS.2011.2177667

Naeimi, V., Scipal, K., Bartalis, Z., Hasenauer, S., \& Wagner, W. (2009). An improved soil moisture retrieval algorithm for ERS and METOP scatterometer observations. IEEE Transactions on Geoscience and Remote Sensing, 47(7), 1999-2013, doi:10.1109/tgrs.2008.2011617

Ngunyen H. H., Kim, H., Choi, M., (2017). Evaluation of the soil water content using cosmic-ray neutron probe in a heterogeneous monsoon climate-dominated region, Advances in Water Resources, In press, https://doi.org/10.1016/j.advwatres.2017.07.020

Njoku, E. G., Jackson, T. J., Lakshmi, V., Chan, T. K., \& Nghiem, S. V. (2003). Soil moisture retrieval from AMSR-E. IEEE transactions on Geoscience and remote sensing, 41(2), 215-229.

Martínez-Fernández, J., \& Ceballos, A. (2005). Mean soil moisture estimation using temporal stability analysis. Journal of Hydrology, 312(1), 28-38, doi:10.1016/j.jhydrol.2005.02.007

Maeda, T., \& Taniguchi, Y. (2013). Descriptions of GCOM-W1 AMSR2 Level 1R and Level 2 Algorithms. Japan Aerospace Exploration Agency Earth Observation Research Center:

McColl, K.A., Vogelzang, J., Konings, A.G., Entekhabi, D., Piles, M. and Stoffelen, A., 2014. Extended triple collocation: Estimating errors and correlation coefficients with respect to an unknown target. Geophysical Research Letters, 41(17), pp.6229-6236, doi: 
Meesters, A. G., De Jeu, R. A., \& Owe, M. (2005). Analytical derivation of the vegetation optical depth from the microwave polarization difference index. IEEE Geoscience and Remote Sensing Letters, 2(2), 121-123, doi:10.1109/lgrs.2005.843983

Mo, T., Choudhury, B. J., Schmugge, T. J., Wang, J. R., \& Jackson, T. J. (1982). A model for microwave emission from vegetation-covered fields. Journal of Geophysical Research: Oceans, 87(C13), 11229-11237

Maeda, T., \& Taniguchi, Y. (2013). Descriptions of GCOM-W1 AMSR2 Level 1R and Level

2 Algorithms. Japan Aerospace Exploration Agency Earth Observation Research Center: Ibaraki, Japan.

Moghaddam, M., Silva, A. R., Clewley, D., Akbar, R., Hussaini, S. A., Whitcomb, J., ... \& 1086 Vannan, S. S. (2016). Soil Moisture Profiles and Temperature Data from SoilSCAPE Sites, USA. ORNL DAAC, Oak Ridge, Tennessee, USA of America Journal, 77(6), 1888-1919, doi:10.2136/sssaj2013.03.0093

O’Neill, P. E., Njoku, E. G., Jackson, T. J., Chan, S., \& Bindlish, R. (2015). SMAP algorithm 1092 theoretical basis document: Level $2 \& 3$ soil moisture (passive) data products. Jet Propulsion 1093 Lab., California Inst. Technol., Pasadena, CA, USA, JPL D-66480

Radiometer Global Daily 36 km EASE-Grid Soil Moisture.

Owe, M., de Jeu, R., \& Holmes, T. (2008). Multisensor historical climatology of satellite- 
derived global land surface moisture. Journal of Geophysical Research: Earth Surface, 113(F1), doi:10.1029/2007JF000769

Owe, M., de Jeu, R., \& Walker, J. (2001). A methodology for surface soil moisture and vegetation optical depth retrieval using the microwave polarization difference index. IEEE Transactions on Geoscience and Remote Sensing, 39(8), 1643-1654, doi:10.1109/36.942542

Pan, M., Cai, X., Chaney, N. W., Entekhabi, D., \& Wood, E. F. (2016). An initial assessment of SMAP soil moisture retrievals using high-resolution model simulations and in situ observations. Geophysical Research Letters, 43(18), 9662-9668, doi:10.1002/2016gl069964

Parinussa, R. M., de Jeu, R. A., van der Schalie, R., Crow, W. T., Lei, F., \& Holmes, T. R. (2016). A Quasi-Global Approach to Improve Day-Time Satellite Surface Soil Moisture Anomalies through the Land Surface Temperature Input. Climate, 4(4), 50, doi:10.3390/cli4040050

Parinussa, R. M., Holmes, T. R., Wanders, N., Dorigo, W. A., \& de Jeu, R. A. (2015). A preliminary study toward consistent soil moisture from AMSR2. Journal of Hydrometeorology, 16(2), 932-947, doi:10.1175/jhm-d-13-0200.1

Parinussa, R. M., Meesters, A. G. C. A., Liu, Y. Y., Dorigo, W., Wagner, W., \& De Jeu, R. A. M. (2011). Error estimates for near-real-time satellite soil moisture as derived from the land parameter retrieval model. Geoscience and Remote Sensing Letters, IEEE, 8(4), 779-783, doi:10.1109/LGRS.2011.2114872

Parrens, M., Zakharova, E., Lafont, S., Calvet, J. C., Kerr, Y., Wagner, W., \& Wigneron, J. P. (2012). Comparing soil moisture retrievals from SMOS and ASCAT over France. Hydrology and Earth System Sciences, 16(2), 423, doi:10.5194/hess-16-423-2012 
Paulik, C., Dorigo, W., Wagner, W., \& Kidd, R. (2014). Validation of the ASCAT Soil Water Index using in situ data from the International Soil Moisture Network. International journal of applied earth observation and geoinformation, 30, 1-8, doi:10.1016/j.jag.2014.01.007

Rodell, M., Houser, P. R., Jambor, U. E. A., Gottschalck, J., Mitchell, K., Meng, C. J., ... \& Entin*, J. K. (2004). The global land data assimilation system. Bulletin of the American Meteorological Society, 85(3), 381-394, doi: 10.1175/BAMS-85-3-381

Rüdiger, C., Calvet, J. -C., Gruhier, C., Holmes, T. R. H., de Jeu, R. A.M., \&Wagner,W. (2009). An intercomparison of ERS-Scat and AMSR-E soil moisture observations with model simulations over France. Journal of Hydrometeorology, 10, doi:10.1175/2008jhm997.1

Sahoo, A. K., Houser, P. R., Ferguson, C., Wood, E. F., Dirmeyer, P. A., \& Kafatos, M. (2008). Evaluation of AMSR-E soil moisture results using the in-situ data over the Little River Experimental Watershed, Georgia. Remote Sensing of Environment, 112(6), 3142-3152, doi:10.1016/j.rse.2008.03.007

Saxton, K. E., \& Rawls, W. J. (2006). Soil water characteristic estimates by texture and organic matter for hydrologic solutions. Soil science society of America Journal, 70(5), 15691578, doi:10.2136/sssaj2005.0117

Scipal, K., Drusch, M., \& Wagner, W. (2008a). Assimilation of a ERS scatterometer derived soil moisture index in the ECMWF numerical weather prediction system. Advances in water resources, 31(8), 1101-1112, doi:10.1016/j.advwatres.2008.04.013

Scipal, K., Holmes, T., De Jeu, R., Naeimi, V., \& Wagner, W. (2008b). A possible solution for the problem of estimating the error structure of global soil moisture data sets. Geophysical Research Letters, 35(24), doi:10.1029/2008g1035599 
Systematic observation requirements for satellite-based products for climate. WMO/TD,

1145 (1338), p.103

Su, C.-H., Ryu, D., Crow, W. T., \& Western, A. W. (2014a). Stand-alone error characterization of microwave satellite soil moisture using a Fourier method. Remote Sensing of Environment, 154, 115-126, doi:10.1016/j.rse.2014.08.014

1149 Su, C. H., Ryu, D., Crow, W. T., \& Western, A.W. (2014b). Beyond triple collocation: Applications to soil moisture monitoring. Journal of Geophysical Research: Atmospheres, 119(11), 6419-6439, doi:10.1002/2013JD021043

Taylor, K. E. (2001). Summarizing multiple aspects of model performance in a single 1153 diagram. Journal of Geophysical Research: Atmospheres, 106(D7), 7183-7192, doi:10.1029/2000jd900719

Ulaby, F. T., Moore, R. K., \& Fung, A. K. (2015). Microwave remote sensing active and 1156 passive

Vachaud, G., Passerat de Silans, A., Balabanis, P., \& Vauclin, M. (1985). Temporal stability of spatially measured soil water probability density function. Soil Science Society of America 1159 Journal, 49(4), 822-828.

1160 van der Schalie, R., de Jeu, R. A. M., Kerr, Y. H., Wigneron, J. P., Rodríguez-Fernández, N. J., Al-Yaari, A., ... \& Drusch, M. (2017). The merging of radiative transfer based surface soil 1162 moisture data from SMOS and AMSR-E. Remote Sensing of Environment, 189, 180-193, 
doi:10.1016/j.rse.2016.11.026

Wagner, W., Brocca, L., Naeimi, V., Reichle, R., Draper, C., de Jeu, R., Ryu, D., Su, C. H., Western, A., Calvet, J. C., \& Kerr, Y. H., Leroux, D. J., Drusch, M., Jackson, T. J., Hahn, S., Dorigo, W., \& Paulik, C. (2014). Clarifications on the "Comparison between SMOS, VUA, ASCAT, and ECMWF soil moisture products over four watersheds in US". Geoscience and Remote Sensing, IEEE Transactions on, 52(3), 1901-1906, doi:10.1109/TGRS.2013.2282172

Wagner, W., Dorigo, W., de Jeu, R., Fernandez, D., Benveniste, J., Haas, E., \& Ertl, M. (2012, August). Fusion of active and passive microwave observations to create an essential climate variable data record on soil moisture. In Proceedings of the XXII International Society for Photogrammetry and Remote Sensing (ISPRS) Congress, Melbourne, Australia (Vol. 25).

Wagner, W., Hahn, S., Kidd, R., Melzer, T., Bartalis, Z., Hasenauer, S., ... \& Komma, J. (2013). The ASCAT soil moisture product: A review of its specifications, validation results, and emerging applications. Meteorologische Zeitschrift, 22(1), 5-33, doi:10.1127/0941$2948 / 2013 / 0399$

Wagner, W., Lemoine, G., \& Rott, H. (1999). A method for estimating soil moisture from ERS scatterometer and soil data. Remote sensing of environment,70(2), 191-207, doi:10.1016/s0034-4257(99)00036-x

Wagner, W., Pathe, C., Doubkova, M., Sabel, D., Bartsch, A., Hasenauer, S., Bloschl, G., Scipal, K., Fernandez, J. M., \& Löw, A. (2008). Temporal stability of soil moisture and radar backscatter observed by the Advanced Synthetic Aperture Radar (ASAR). Sensors, 8(2), 11741197, doi:10.3390/s80201174

Wagner, W., Scipal, K., Pathe, C., Gerten, D., Lucht, W., \& Rudolf, B. (2003). Evaluation of the agreement between the first global remotely sensed soil moisture data with model and 
precipitation data. Journal of Geophysical Research: Atmospheres, 108(D19), doi:10.1029/2003jd003663

Walker, J. P. \& Houser, P. R. (2004). Requirements of a global near-surface soil moisture satellite mission: accuracy, repeat time, and spatial resolution. Advances in water resources, 1190 27(8), 785-801, doi:10.1016/j.advwatres.2004.05.006

Whalley, W. R. (1993). Considerations on the use of time-domain reflectometry (TDR) for measuring soil water content. European Journal of Soil Science, 44(1), 1-9. doi:10.1111/j.13652389.1993.tb00429.x

Wilson, M. F., \& Henderson-Sellers, A. (1985). A global archive of land cover and soils data 1195 for use in general circulation climate models. Journal of Climatology, 5(2), 119-143, doi:10.1002/joc.3370050202

1197 Zeng, J., Chen, K. S., Bi, H., \& Chen, Q. (2016). A preliminary evaluation of the SMAP 1198 radiometer soil moisture product over United States and Europe using ground-Based measurements. IEEE Transactions on Geoscience and Remote Sensing, 54(8), 4929-4940, doi:10.1109/tgrs.2016.2553085

Zohaib, M., H., Kim, and M., Choi (2017), Evaluating the Patterns of Spatiotemporal Trends Research: Atmospheres, 122, doi:10.1002/2016JD026379.

Zreda, M., Shuttleworth, W. J., Zeng, X., Zweck, C., Desilets, D., Franz, T., \& Rosolem, R. 1205 (2012). COSMOS: the cosmic-ray soil moisture observing system. Hydrology and Earth 